\title{
Deposit insurance and the coexistence of commercial and shadow banks
}

\author{
Stephen F. LeRoy ${ }^{1} \cdot$ Rish Singhania ${ }^{2}$
}

Received: 11 June 2019 / Accepted: 5 January 2020 / Published online: 22 January 2020

(c) The Author(s) 2020

\begin{abstract}
We investigate how deposit insurance affects the structure of the financial system in a general equilibrium setting in which a government insurer guarantees deposits at commercial banks, but not at shadow banks. With deposit-based or risky-asset-based insurance premia, price distortions induced by subsidized deposit insurance benefit shadow banks, by allowing these banks to trade to their advantage. Insured commercial banks and uninsured shadow banks coexist under subsidized deposit insurance. Capital requirements on commercial banks make shadow banking more attractive. The asset price distortion is eliminated when the aggregate subsidy to unsuccessful commercial banks equals the aggregate penalty to successful banks.
\end{abstract}

Keywords Deposit insurance $\cdot$ Shadow banks · Bank regulation · Capital requirements

\section{JEL Classification G21 · G23 · G28}

Government insurance of commercial bank deposits has been controversial, especially after the recent financial crisis. ${ }^{1}$ The role of deposit insurance in eliminating costly bank runs is widely recognized, but critics point out that such insurance also has adverse effects: it may subsidize risk-taking by insured banks at the expense of the taxpayer. Also, the financial crisis featured runs by investors on the so-called shadow banking system, reflecting the fact that depositors at these institutions do not benefit

\footnotetext{
1 The International Association of Deposit Insurers (www.iadi.org) reports that 113 countries had some form of explicit deposit insurance as of January 31, 2014; see Demirguc-Kunt et al. (2008) for a discussion of factors that influence the adoption and design of deposit insurance by countries. Demirguc-Kunt and Kane (2002) document cross-country differences in the performance of deposit insurance programs.
}

$凶$ Rish Singhania

h.singhania2@exeter.ac.uk

Stephen F. LeRoy

leroy@ucsb.edu

1 Dept. of Economics, University of California Santa Barbara, Santa Barbara, CA 93106, USA

2 Business School, University of Exeter, 1.31 Streatham Court, Exeter EX4 4PU, UK 
directly from deposit insurance. ${ }^{2}$ The following questions arise. How do shadow banks compete with commercial banks when commercial banks but not shadow banks have access to insurance, particularly when the insurance is subsidized, as is generally believed to be the case? How do commercial banks interact with shadow banks in the setting just described $?^{3}$ More generally, how does the design of the deposit insurance program affect the structure of the financial system?

To answer these questions, we investigate the effects of deposit insurance in a general equilibrium setting under the assumptions that banking is competitive and that agents can either turn over assets to commercial banks in exchange for insured deposits or hold assets in uninsured shadow banks. The latter option avoids both the direct benefits and (non lump-sum) costs of deposit insurance. We study how deposit insurance affects the structure of the financial system under different financing regimes and for arbitrary levels of insurance premia. The general equilibrium setting also allows us to ascertain how the financing regimes and insurance premia affect asset prices.

If deposit insurance subsidizes commercial banks, bank owners enjoy all gains on investment but bear only part of investment losses, inducing them to take on more risk than they would otherwise. ${ }^{4}$ As a result equilibrium asset prices are distorted. The direction of the distortion depends on whether the premium is charged against deposits, in which case risky assets are overpriced, or on risky asset holdings, in which case the opposite can occur. If the subsidy is high enough—meaning that the insurance premium per dollar of deposits issued, or risky assets held, is below a threshold level—all agents use commercial banks so as to take advantage of underpriced deposit insurance. In that case there is no shadow banking system.

Casual intuition suggests that commercial banks dominate shadow banks as long as deposit insurance subsidizes commercial banks. Contrary to this intuition, we find that commercial banks and shadow banks coexist under subsidized deposit insurance, provided that the subsidy is not too great. Agents are willing to patronize shadow banks, thereby forgoing the direct subsidy to commercial banks, because they know that they will be able to trade to their advantage after the realization of asset shocks. The trading advantage arises because asset prices reflect distortions induced by trades of commercial banks subject to deposit insurance. Therefore subsidized deposit insurance indirectly benefits shadow banks. For a range of insurance premium levels the indirect benefit of deposit insurance to shadow banks exactly equals the direct benefit to commercial banks. The structure of the financial system, given by the mix of commercial and shadow banks, is determined by the size of the insurance subsidy.

The coexistence result applies for both deposit-based premia and risky-asset-based premia. However, there is a crucial difference between the two financing regimes. With

\footnotetext{
2 In practice, both commercial and shadow banks engage in maturity transformation, broadly defined. The distinguishing features of shadow banks are that they are less regulated and do not have access to the Federal Reserve's discount window or Federal deposit insurance; for an overview of shadow banking see Gorton (2010), Adrian and Shin (2010) and Pozsar et al. (2013).

${ }^{3}$ Existing studies focus primarily on how bank regulation in the form of capital requirements imposed on commercial banks generate opportunities for regulatory arbitrage via the shadow banking system; see, for example, Kashyap et al. (2010), Acharya et al. (2013), Gorton and Metrick (2013), Plantin (2015) and references therein.

${ }^{4}$ The implications of moral hazard in the context of deposit insurance were pointed out in the classic paper of Kareken and Wallace (1978); see also Pyle (1984), Kareken (1983) and Suarez (1993).
} 
deposit-based premia, shadow banks sell risky assets to commercial banks after asset shock realizations. As a consequence, risky assets end up in portfolios of commercial banks. The opposite is true with risky-asset-based premia: risky assets end up in portfolios of shadow banks, who buy these assets from commercial banks. Therefore the design of the deposit insurance program has important implications for the distribution of risk within the financial system.

The result that commercial and shadow banks coexist under subsidized deposit insurance has not been stated before, to our knowledge. Analysts missed this result due to reliance on partial equilibrium analysis, which does not address the effects of deposit insurance on equilibrium asset prices. In contrast, the general equilibrium setting specified here allows explicit analysis of the interaction between institutions directly affected by deposit insurance and institutions not so affected. The design of the deposit insurance scheme determines interactions between the two types of institutions, and therefore has important implications for the structure of the financial system.

Following public criticism of bank bailouts during the recent financial crisis, many governments pledged to end taxpayer subsidies to banks. The simplest representation of a setting in which bank deposit insurance entails no bank subsidies is that it be actuarially fair bank by bank and date by date. Actuarial fairness requires that insurance premia be continually adjusted for each bank at each date in response to changes in portfolios and asset values so as to equal that bank's expected insurance payout. ${ }^{5}$ The requirement of actuarial fairness is unrealistically strong: insurance regulators cannot continually fine-tune insurance premia as actuarial fairness requires.

We analyze deposit insurance programs that satisfy the weaker condition of revenue neutrality, meaning that aggregate revenue from insurance premia is equal to aggregate insurance payments to failed banks, so that the aggregate taxpayer subsidy to banks is zero. ${ }^{6}$ Premia will be actuarially unfair for individual banks to the extent that their returns differ from returns averaged over banks and over time.

A major finding of this paper is that in the setting just described deposit insurance affects asset prices, relative to the prices that would otherwise prevail, if and only if the premia are revenue favorable to commercial banks, meaning the aggregate taxpayer subsidy to commercial banks is positive. If premia are revenue neutral, so that the aggregate subsidy to commercial banks is zero, there is no distortion in asset prices. This obtains despite the fact that, as noted, revenue neutrality is consistent with deposit insurance not being actuarially fair bank by bank and date by date. This conclusion is true in our model under both deposit-based and risky-asset-based insurance premia.

\footnotetext{
5 Actuarial fairness implies absence of distortion, at least under risk-neutrality: if the insurer can observe bank behavior and adjust premia one-for-one in response to changes in expected insurance transfers, then risk-neutral bankers are indifferent as to the existence or nonexistence of deposit insurance; see Prescott (2002). In earlier work, Merton (1977) used option pricing theory to derive an analytic formula for the actuarially fair level of the insurance premium.

6 Revenue neutral deposit insurance is sometimes referred to as fairly priced deposit insurance; see e.g., Allen et al. (2015).
} 
We believe that our result that revenue-neutral but actuarially unfair deposit insurance does not distort asset prices is novel. ${ }^{7}$

In our setting there exists an important difference between the revenue-neutral equilibria depending on whether premia are charged against deposits or risky assets. The former case features a continuum of revenue-neutral equilibria that are non-trivial, that is, in which aggregate insurance collections equal aggregate payouts, and are also nonzero. In contrast, the latter case features a unique revenue-neutral equilibrium, and one that is trivially so. Commercial banking collapses with revenue-neutral riskyasset-based premia. This finding suggests that if policy-makers want to implement an insurance program that does not distort asset prices, but also does not shut down commercial banks, they must look towards deposit-based premia, instead of riskyasset-based premia.

We add to the rapidly growing literature on commercial bank regulation by studying how the design of deposit insurance affects incentives for commercial banks to shift assets to the shadow banking sector. One of our key results is that deposit-based insurance premia do not generate such incentives, provided the premium level is either revenue favorable to commercial banks or non-trivially revenue neutral. Risky-assetbased deposit insurance premia, however, induce commercial banks to shift risky assets to shadow banks. This finding is important because it suggests that the recent push towards charging risky-asset-based premia for deposit insurance might shift risky assets into financial institutions that are generally less resilient to shocks.

Motivated by current debate surrounding bank capital regulation, we also study how imposing capital requirements on commercial banks affects the structure of the financial system in our setting, for different insurance regimes and for arbitrary levels of insurance premia. Our analysis indicates that the effect of capital requirements is similar to that of increased insurance premia: both reduce the deposit insurance subsidy to commercial banks. As a consequence, higher capital requirements make shadow banking more attractive, relative to commercial banking. It follows that, for insurance premium levels at which commercial and shadow banks coexist in equilibrium, higher capital requirements increase the measure of shadow banks operating in equilibrium. ${ }^{8}$ Our general equilibrium setting also sheds light on how the interaction between commercial bank regulation and the shadow banking system affects asset prices. We find that, given an insurance premium level, capital requirements reduce the asset price distortion induced by deposit insurance.

\section{Related literature}

Our paper is related to a rapidly growing literature that studies government regulation of commercial banks in the presence of a less regulated shadow banking sector.

\footnotetext{
7 Allen et al. (2015) study optimal bank capital structure, in the presence of bankruptcy costs, under revenueneutral deposit insurance with fixed premia. Our analysis complements that study by characterizing asset price distortions due to deposit insurance, for more general insurance premia, when agents can direct assets to shadow banks.

8 This finding agrees with the claim in Kashyap et al. (2010) and Adrian and Ashcraft (2012) that higher capital requirements might increase shadow banking activity; see also Plantin (2015).
} 
Ordonez (2018) shows that, with reputational concerns, shadow banking improves welfare if regulations on commercial banks limit their ability to fund risky projects with positive NPV. Hanson et al. (2015) study commercial and shadow bank portfolios when liabilities issued by both banks provide transaction services to households. Building on Hanson et al. (2015), Lyonnet and Chrétien (2017) provide conditions under which the possibility of a financial crisis in the future leads to coexistence of commercial and shadow banks. Luck and Schempp (2014) present a model in which the size of the shadow banking system, relative to secondary asset markets, matters for stability of both commercial and shadow banks. Górnicka (2016) presents a model in which commercial and shadow banks are complements, and therefore coexist, in the presence of government guarantees to commercial banks. Grochulski and Zhang (2016) study how the presence of shadow banks as an outside-option affects optimal liquidity regulation of commercial banks. Plantin (2015) presents a model in which excessively tight capital requirements can have the perverse effect of moving risky assets from commercial banks to the shadow banking sector. Harris et al. (2015) study how capital requirements imposed on commercial banks affect welfare in a general equilibrium setting where banks compete with market-based financing of loans.

In addition to the literature cited above, the asset-pricing mechanism our paper is related to a large literature on asset overvaluation; see Brunnermeier and Oehmke (2013) for a survey. In that literature, our paper is related to studies in which riskshifting due to limited liability generates overvaluation of risky assets; see, e.g., Allen and Gale (2000), Barlevy (2014) and Dow and Han (2015). ${ }^{9}$

\section{The model}

There are three dates: 0,1 and 2 . The economy is populated by a continuum of risk neutral agents, indexed by $i \in[0,1]$, who consume at date 2 . Each agent has a date0 endowment consisting of one unit each of a riskless asset and a risky asset. It is assumed that each agent allocates his entire endowment to his own personal bank, which may be either a commercial bank or a shadow bank; we use $i$ to index banks as well. ${ }^{10}$ If he chooses a commercial bank he receives in exchange insured deposits $d$ and bank equity $e_{0}^{c}$, the values of which are expressed in units of date- 2 consumption. Alternatively, if he chooses a shadow bank he receives bank equity $e_{0}^{s}$ in exchange.

The riskless asset is costlessly storable from date 0 to date 1 , and from date 1 to date 2, when it transforms into one unit of a consumption good. At date 1 each bank's holding of the risky asset is subject to a multiplicative productivity shock $\varepsilon_{1}(i)$, different for different banks, so that it becomes $\varepsilon_{1}(i)$ units of the asset at date 1 . At date 2 another multiplicative shock $\varepsilon_{2}(i)$ occurs, resulting in $\varepsilon_{1}(i) \varepsilon_{2}(i)$ units of the

\footnotetext{
9 Allen and Gorton (1993) study overvaluation due to a similar agency problem that arises because of call options implicit in managerial compensation.

10 An alternative would be to allow each agent to divide his investment among several, or many, banks. However, this specification would result in banks with different relative holdings of risky and riskless assets, which in turn would result in different banks paying different deposit interest rates due to risk differences. Taking this path is tractable, but would refocus the model on the agency problem between bank depositors and bank owners, a phenomenon already much studied. The adopted specification allows us to concentrate on the agency problem between bank owners and the insurer.
} 
consumption good. The shocks $\varepsilon_{1}(i)$ and $\varepsilon_{2}(i)$ of each bank are uniformly distributed on the interval $[\underline{\varepsilon}, \bar{\varepsilon}]$, independently of each other and of the shocks of other banks. For brevity, we will sometimes adopt notation that suppresses the dependence of the shocks on $i$ and denote them as $\varepsilon_{1}$ and $\varepsilon_{2}$.

We utilize a version of the law of large numbers to characterize the sample distribution of the shocks, implying that the realizations of $\varepsilon_{1}$ and $\varepsilon_{2}$ are uniformly distributed, like the population distribution of each bank's $\varepsilon_{1}$ and $\varepsilon_{2} .{ }^{11}$

After the realization of the date- 1 productivity shocks $\varepsilon_{1}$, banks can trade risky and riskless assets with other banks in a perfectly competitive market. We denote the net purchase of risky assets by the bank of a given agent by $x\left(\varepsilon_{1}(i)\right)$ to reflect the dependence of the optimal choice of $x$ on $\varepsilon_{1}(i)$. Again, we will abbreviate $x\left(\varepsilon_{1}(i)\right)$ by $x$. It is assumed that banks cannot issue, retire or transfer deposits at date 1 , implying that banks cannot use deposits to pay for asset purchases; the same applies to equity. Instead, banks draw down or augment their holdings of the riskless asset according to whether they are buyers or sellers of the risky asset. This device, although artificial, serves to ensure that asset transactions lie in a bounded interval, implying existence of optima. Banks buy or sell the risky asset at date 1, subject to the no short-sales constraint, in order to maximize date-1 bank values.

At date 2 risky assets are subject to random productivity shocks $\varepsilon_{2}$. After the realization of the shocks, banks are liquidated: deposits at commercial banks (augmented by transfers from the insurer if the bank is insolvent) and bank equity are withdrawn in the form of the physical good, which the agents then consume.

Throughout the paper we identify the shocks with the holder of the risky asset rather than with the asset itself. For example, if bank $i$ buys $x$ units of the risky asset from bank $i^{\prime}$ at date 1 , as will occur under deposit insurance, the newly acquired asset undergoes the date 2 shock of bank $i$, not that of bank $i^{\prime}$. At date 2, the risky asset holdings of the bank $i$ transform into $\left(\varepsilon_{1}(i)+x\left(\varepsilon_{1}(i)\right)\right) \varepsilon_{2}(i)$ units of the consumption good. The identification of shocks with the holder of the asset is a reduced form way of generating idiosyncratic risk at the bank level. Without such risk, the assumption that asset returns are contemporaneously independent implies that returns on diversified bank portfolios are deterministic with probability one, trivializing the analysis of deposit insurance. The real world counterpart to the assumption of holder-specific shocks is the net shock to return on the asset-holdings of a bank. As in the real world, banks in the model acquire risky assets from other banks and continue to face undiversifiable risk.

\footnotetext{
${ }^{11}$ In appealing to "a version of the law of large numbers" we follow a standard practice in applied general equilibrium analysis of sidestepping a difficulty involved in modeling sample outcomes generated by a continuum of realizations of independent random variables: the difficulty is that for any $Y \in[\varepsilon, \bar{\varepsilon}]$ the set of realizations for the event $\varepsilon_{1} \leq Y$ is nonmeasurable with probability 1 , implying that the usual characterization of the cumulative distribution function $P(y)=\operatorname{prob}(Y \leq y)$ is not available. Thus the simplest justifications for the law of large numbers do not apply. This problem was first pointed out by Judd (1985) and Feldman and Gilles (1985). Several methods can be used to justify the law of large numbers; see Uhlig (1996). Most simply and intuitively, in this setting the sample distribution of a finite number of independent draws converges to the uniform distribution as the number of draws becomes large. Therefore the appeal to the law of large numbers can be justified informally using a limiting argument. Duffie and Sun (2007, 2012) followed Feldman and Gilles in applying nonstandard analysis to demonstrate the limiting result rigorously.
} 
A bank insurer guarantees all deposits at commercial banks. It does this by supplying funds at date 2 in an amount just sufficient to enable failed commercial banks (those with low realizations of $\varepsilon_{1}$ and $\varepsilon_{2}$ ) to pay depositors fully. Depending on the model version, the bank insurer finances the insurance transfer using lump-sum taxes $t$ or insurance premia $j$ (where $j$ is applied to deposit levels or risky asset holdings), or both. Commercial banks pay the insurance premium to the bank insurer after liquidation at date 2. Commercial banks with date-2 assets less than $d+j$ fail. The insuring agency confiscates the assets of failed banks and pays the deposit liabilities of these banks in full. The insurance premium paid by failed banks equals the value of the assets net of deposit payments if that number is positive, zero otherwise. Equity holders of failed banks experience a $100 \%$ loss. At date 2 depositors are paid their deposits, without interest, by all commercial banks regardless of returns on bank-held assets.

Shadow banks Agents can instead elect to transfer their assets to shadow banks, which differ from commercial banks in that they do not participate in the deposit insurance program. To simplify notation we set deposits at shadow banks equal to zero. Thus the convention is that the entire value of shadow banks consists of equity, implying that shadow banks are never insolvent. ${ }^{12}$ These shadow banks can be interpreted as uninsured subsidiaries of commercial banks. More generally, they can be thought of as financial market participants that trade assets with commercial banks, but do not benefit from explicit deposit insurance. Examples include money market mutual funds, insurance firms, hedge funds, structured investment vehicles etc.

Alternatively, we could specify that shadow banks, like commercial banks, issue both deposits and equity at date 0 . Under that specification solvent shadow banks would pay interest on deposits in whatever amount equates the expected return on deposits to the expected return on equity, reflecting agents' assumed risk neutrality. This specification would require that banks be able to precommit to investment strategies, since the appropriate interest rate would depend on how much risk banks take. However, doing so would complicate the notation unnecessarily: the Modigliani-Miller theorem implies that depositors at shadow banks would be indifferent to the division of their assets between equity and (uninsured) deposits. It is simpler to set deposits at shadow banks equal to zero.

Lump-sum taxes $t$ are levied against the date-2 consumption of all agents, regardless of whether they invest in commercial or shadow banks. It is assumed throughout that consumption sets are unbounded below as well as above, ensuring that agents will always be able to pay the tax.

\subsection{Optimization problems}

We use the superscript $c$ for variables related to commercial banks and the superscript $s$ for those related to shadow banks.

\footnotetext{
12 It is seen that starting a shadow bank is equivalent to holding assets in individual portfolios. One could therefore change the terminology to avoid reference to shadow banks; this is a matter of preference. We find it useful to interpret holding assets in individual portfolios as shadow banks.
} 
Commercial bank's optimization problem Date-2 equity $e_{2}^{c}$ for commercial banks is

$$
e_{2}^{c}\left(\varepsilon_{2}, x^{c}, \varepsilon_{1}, d\right)=\max \left[\left(\varepsilon_{1}+x^{c}\right) \varepsilon_{2}+1-\pi_{1} x^{c}-d-j, 0\right],
$$

where $x^{c}$ denotes purchases of the risky asset by commercial banks at date 1 and $\pi_{1}$ is the equilibrium date- 1 price of the risky asset relative to the riskless asset.

At date 1, commercial banks choose asset trades $x^{c}$ to maximize expected date-2 equity values. Since commercial banks can only buy risky assets by selling riskless assets, or vice-versa, asset trades must lie in the interval $\left[-\varepsilon_{1}, 1 / \pi_{1}\right]$. The equity value maximization problem at date 1 is

$$
e_{1}^{c}\left(\varepsilon_{1}, d\right)=\max _{x^{c} \in\left[-\varepsilon_{1}, 1 / \pi_{1}\right]} \mathbb{E}\left\{e_{2}^{c}\left(\varepsilon_{2}, x^{c}, \varepsilon_{1}, d\right) \mid \varepsilon_{1}\right\}
$$

Commercial banks choose how much deposits and equity to issue at date 0 , subject to the constraint that their summed value equals the value of the agent's endowment. We assume that the bank insurer mandates an upper bound $d^{*}$ for the level of deposits at commercial banks, $d \in\left[0, d^{*}\right]$. The upper bound $d^{*}$ can be interpreted as a cap on the level of insured deposits. ${ }^{13}$ In practice, deposit insurance agencies routinely impose such a cap. For example, the FDIC insures up to $\$ 250,000$ of deposits for each depositor at an institution. As we will see below, this upper bound on deposits (or a similar modeling device) is necessary for a determinate equilibrium in our setting. We have

$$
V^{c}=\max _{d \in\left[0, d^{*}\right]} d+\mathbb{E}\left\{e_{1}^{c}\left(\varepsilon_{1}, d\right)\right\}
$$

where $V^{c}$ denotes the date- 0 value of commercial banks.

Shadow bank's optimization problem The date-2 value of shadow bank equity is

$$
e_{2}^{s}\left(\varepsilon_{2}, x^{s}, \varepsilon_{1}\right)=\left(\varepsilon_{1}+x^{s}\right) \varepsilon_{2}+1-\pi_{1} x^{s}
$$

which differs from the commercial bank's equity in that deposits and the insurance premium are both zero and also reflects the fact that shadow banks, not issuing deposits, cannot fail. At date 1 , shadow banks choose asset trades $x^{s}$ to maximize equity value:

$$
e_{1}^{s}\left(\varepsilon_{1}\right)=\max _{x^{s} \in\left[-\varepsilon_{1}, 1 / \pi_{1}\right]} \mathbb{E}\left\{e_{2}^{s}\left(\varepsilon_{2}, x^{s}, \varepsilon_{1}\right) \mid \varepsilon_{1}\right\}
$$

Shadow banks make no choices at date 0 , implying that date- 0 equity value is

$$
V^{s}=\mathbb{E}\left\{e_{1}^{s}\left(\varepsilon_{1}\right)\right\}
$$

\footnotetext{
13 Instead of specifying an upper bound on deposits, we could allow commercial banks to issue arbitrary levels of deposits subject to an upper bound on insured deposits. Because the Modigliani-Miller theorem applies to uninsured deposits and equity, the equilibrium in that case would be identical to the one we study.
} 
Agent's optimization problem At date 0, agents choose whether to invest in commercial or shadow banks. Since agents invest their entire endowment in a single bank, expected date- 2 consumption of agents equals the date- 0 value of the bank in which the agent invests. It follows that the consumption maximization problem is

$$
\max \left[V^{s}, V^{c}\right]
$$

Since agents pay lump-sum taxes regardless of whether they direct their endowment to commercial or shadow banks, these taxes do not feature in the consumption maximization problem.

\section{Equilibrium}

To characterize the equilibrium we define a function $m$ mapping the interval $[0,1]$ onto $\{c, s\}$, where $m(i)=c$ or $s$ according to whether agent $i$ directs his date- 0 endowment to a commercial or shadow bank. He will choose whichever bank provides him with higher expected date- 2 consumption, with his choice being prescribed arbitrarily as part of the characterization of equilibrium in the case of indifference.

The assumption that each agent invests all of his or her endowment in the same bank (either a commercial bank or a shadow bank) implies that risky and riskless assets do not have well-defined individual values at date 0 . We are led to define a new composite commodity - consisting of one unit of the risky asset and one unit of the riskless asset-that reflects the composition of each agent's endowment. The value (again, relative to date- 2 consumption) at date 0 of this composite commodity is well defined and equals $\max \left[V^{c}, V^{s}\right]$.

A competitive equilibrium consists of investment choice by agents $m(i)$; commercial and shadow bank values $\left\{V^{c}, V^{s}\right\}$; deposits at commercial banks $d$; date-1 asset trades by commercial and shadow banks $\left\{x^{c}, x^{s}\right\}$; date-1 relative price of the risky asset $\pi_{1}$; an insurer-mandated upper bound on deposits at commercial banks $d^{*}$; and lump-sum taxes $t$ such that

1. Agent $i$ chooses whether to allocate his endowment to a commercial bank, $m(i)=$ $c$, or a shadow bank, $m(i)=s$, so as to maximize expected date- 2 consumption.

2. Commercial and shadow banks choose asset trades $\left\{x^{c}, x^{s}\right\}$ at date 1 to maximize expected date- 2 equity values. Commercial banks choose deposit levels $d$ at date 0 to maximize expected date- 2 consumption of depositors.

3. The date-1 market for risky assets clears at the relative price $\pi_{1}$.

4. The upper bound on deposits $d^{*}$ is the highest level of $d$ such that, for every realization of $\varepsilon_{1}(i)$, there exists an admissible net trade $x$ and a realization of $\varepsilon_{2}(i)$ (under the net trade $x$ ) for which each commercial bank $i$ survives at date 2 .

5. The bank insurer balances its budget: lump sum taxes $t$ equal the difference between total insurance payments made and total insurance premia collected.

In our setting, the upper bound on deposits $d^{*}$, or a similar device, is necessary to determine the equilibrium. Otherwise, for $d>d^{*}$, commercial banks with sufficiently low values of $\varepsilon_{1}$ would be certain to fail at date 2 . These banks have no stake in the 
returns on their investments. They would be indifferent as to whether to buy or sell the risky asset at date 1, or do nothing: the date- 2 value of the equity of such banks is zero under any of these courses of action. This indeterminacy in commercial banks' investment decisions would result in an indeterminacy in equilibrium prices, since at date 0 all commercial banks run the risk of being certain at date 1 of failing at date 2 . Rather than complicate the analysis of the model by incorporating this case we rule out indeterminacy by assuming that the insurer enforces the restriction $d \leq d^{*}$, so that all commercial banks are constrained to choose levels of $d$ such that for all realizations of $\varepsilon_{1}$ at date 1 they have positive probability of remaining solvent at date $2 .{ }^{14}$ Since a commercial bank must pay both deposits and the insurance premium to survive, the maximum level of deposits permitted by the insurer also depends on $j$.

\subsection{No deposit insurance}

In this section a simple model without deposit insurance is specified. Since we have defined commercial banks as banks that issue insured deposits, the modification corresponds to assuming that there are no commercial banks, $m(i)=s$ for all $i \in[0,1]$. This model will serve as a benchmark against which to compare the equilibrium prices of assets when we alter the model in subsequent sections to allow existence of commercial banks.

Proposition 1 The fundamental value of the risky asset at date-1 is $[\underline{\varepsilon}+\bar{\varepsilon}] / 2$. The fundamental date-0 value of shadow banks is $V^{s}=[\underline{\varepsilon}+\bar{\varepsilon}]^{2} / 4+1$. In the absence of deposit insurance, the equilibrium date-1 relative price of the risky asset equals its fundamental value, implying that agents have no motivation to trade assets.

\subsection{Lump-sum tax financed deposit insurance}

We assume that deposit insurance is financed entirely via a lump-sum tax $t$; doing so makes it possible to separate the effects of deposit insurance from the effects of how the insurance is financed. Therefore the environment in this section is a special case of the environment laid out in Sect. 2: here, insurance premia $j$ equal zero for all commercial banks.

We begin with a partial equilibrium analysis in which we conjecture a symmetric equilibrium: all agents set up commercial banks, $m(i)=c$ for all $i \in[0,1]$, and all banks issue the same level of deposits $d$ at date 0 . Initially we take $d$ as given. The findings from the partial equilibrium analysis are summarized in Proposition 2. In the last subsection of this section (Proposition 3) we will broaden the analysis to determine equilibrium by considering whether agents are motivated to deviate from the

\footnotetext{
14 It would seem that one could avoid the indeterminacy problem by specifying that commercial banks that are certain to fail cannot trade assets. This restriction in fact does not resolve the problem. Even if commercial banks that are certain to fail are prohibited from trading assets, the imputed date- 1 asset values for these banks are not well defined, implying that the equilibrium date-0 values of the risky and the riskless asset are indeterminate.

We choose to rule out these indeterminacies because they are consequences of the details of our model specification, and do not seem to correspond to real-world phenomena.
} 
conjectured equilibrium by choosing a different level of $d$ as deposits at commercial banks, or turning over their assets to shadow banks rather than commercial banks.

Proposition 2 The set of admissible levels of $d$ can be divided into three regions demarcated by boundary points $d^{I-I I}$ and $d^{I I-I I I}$. Each region has different price distortions relative to the no deposit insurance case:

Region I When $d \in\left[0, d^{I-I I}\right]$, the date- 0 value of the endowment equals its expected direct payoff, and the date-1 price of the risky asset relative to the riskless asset is undistorted (i.e., equal to its value in the no deposit insurance case).

Region II When $d \in\left(d^{I-I I}, d^{I I-I I I}\right]$, the endowment at date- 0 is overvalued relative to payoffs. The date-1 price of the risky asset relative to the riskless asset is undistorted.

Region III When $d \in\left(d^{I I-I I I}, d^{*}\right]$, the date-0 endowment is overvalued relative to its payoff and the risky asset at date 1 is overvalued relative to the riskless asset.

Here $d^{I-I I} \equiv(\underline{\varepsilon}+2 /(\underline{\varepsilon}+\bar{\varepsilon})) \underline{\varepsilon}, d^{I I-I I I} \equiv 2 \underline{\varepsilon} \sqrt{1 /(\underline{\varepsilon}+\bar{\varepsilon})^{2}+\underline{\varepsilon} /(\underline{\varepsilon}+\bar{\varepsilon})+\bar{\varepsilon}^{2} / 4}$ and $d^{*}=\left(\underline{\varepsilon}+1 / \pi_{1}\right) \bar{\varepsilon}$.

Derivation of Region I To begin the characterization of the equilibrium for different values of deposits $d$ at commercial banks, consider first the case in which $d$ is so low that all commercial banks will be able to pay off their depositors regardless of their draws of $\varepsilon_{1}$ and $\varepsilon_{2}$, and regardless of how many units of the risky asset they buy or sell at date 1 . The worst possible outcome for a commercial bank is to experience the productivity shock $\underline{\varepsilon}$ at date 1 , exchange its endowment of the riskless asset for the risky asset at the equilibrium relative price $\pi_{1}$ and experience another draw of $\underline{\varepsilon}$ at date 2. If $d$ is low enough that this bank is able to honor its obligation to depositors, then all commercial banks can do so.

Lemma 1 If $d \leq\left(\underline{\varepsilon}+1 / \pi_{1}\right) \underline{\varepsilon} \equiv d^{I-I I}$ then all commercial banks can honor their deposit obligations regardless of their realizations of $\varepsilon_{1}$ and $\varepsilon_{2}$.

When deposits are low enough, $d \leq d^{I-I I}$, Lemma 1 implies that the date-1 equity maximization problem (2) simplifies to

$$
\max _{x^{c} \in\left[-\varepsilon_{1}, 1 / \pi_{1}\right]} \varepsilon_{1} \frac{\underline{\varepsilon}+\bar{\varepsilon}}{2}+1+\left(\frac{\underline{\varepsilon}+\bar{\varepsilon}}{2}-\pi_{1}\right) x^{c}-d .
$$

Since the objective function in (8) is affine in $x$, all banks would buy $1 / \pi_{1}$ units of the risky asset if $\pi_{1}<(\underline{\varepsilon}+\bar{\varepsilon}) / 2$. Banks would go to the other extreme if $\pi_{1}>$ $(\underline{\varepsilon}+\bar{\varepsilon}) / 2$ : all banks would sell $\varepsilon_{1}$ units of the risky asset. It follows that only $\pi_{1}=$ $(\underline{\varepsilon}+\bar{\varepsilon}) / 2$ is consistent with market clearing. The intuition for this finding is simple: when deposits are low enough, commercial banks with different realizations of $\varepsilon_{1}$ do not have comparative advantages or disadvantages in holding the risky asset. Therefore they have no incentive to trade at date 1 if each asset is valued at the expectation of its direct payoff, as in the no deposit insurance case.

All commercial banks will pay off depositors at date 2 and pay whatever remains to equity holders. With no commercial bank failures, the deposit insurer will set $t$ equal 
to zero. The equilibrium value of the endowment at date 0 is $[\underline{\varepsilon}+\bar{\varepsilon}]^{2} / 4+1$, also as when there is no insurance. The expression for $d^{I-I I}$, the upper bound for Region I, is obtained by substituting the equilibrium value $\pi_{1}=(\underline{\varepsilon}+\bar{\varepsilon}) / 2$ in the expression for $d^{I-I I}$ in Lemma 1.

Derivation of Region II Now suppose that $d$ is higher than $d^{I-I I}$, so that commercial banks with low $\varepsilon_{1}$ may fail if $\varepsilon_{2}$ is also low. Commercial banks with a positive probability of failure at date 1 (those with low realizations of $\varepsilon_{1}$ ) value the risky asset above its expected direct date-2 payoff because they can shift the left tail of the payoff distribution to the bank insurer in case of failure. Therefore banks with low realizations of $\varepsilon_{1}$ have a comparative advantage in holding the risky asset, relative to commercial banks that will not fail (those with high realizations of $\varepsilon_{1}$ ). If $d$ is only slightly higher than $d^{I-I I}$ the few commercial banks with very low $\varepsilon_{1}$ that may fail will be dominated by the large majority of commercial banks that will not fail. Motivated by this intuition, we conjecture that the equilibrium relative price of the risky asset at date 1 that prevailed in Region I, $\pi_{1}=(\underline{\varepsilon}+\bar{\varepsilon}) / 2$, will carry over to Region II. That this conjecture is correct will emerge as an implication of the Region II equilibrium, which is now derived.

The event of bank $i$ failing depends on the realization of its date- 1 shock $\varepsilon_{1}$, its net risky asset purchase $x^{c}$ and its realization of the date- 2 shock $\varepsilon_{2}$. Let $\widetilde{\varepsilon}_{2}\left(\varepsilon_{1}, x^{c}\right)$ denote the value of the date- 2 shock $\varepsilon_{2}$ that just enables a commercial bank with date- 1 shock $\varepsilon_{1}$ that buys $x^{c}$ units of the risky asset at date 1 to pay off its depositors (leaving nothing for the equity holders, but not requiring a transfer from the insurer). We have

$$
\widetilde{\varepsilon}_{2}\left(\varepsilon_{1}, x^{c}\right)=\min \left[\bar{\varepsilon}, \max \left[\underline{\varepsilon}, \frac{d+\pi_{1} x^{c}-1}{\varepsilon_{1}+x^{c}}\right]\right],
$$

where the min and max operators ensure that the failure threshold lies in the support of the distribution of shocks.

Commercial banks with high realizations of $\varepsilon_{1}$ will not fail, regardless of their net risky asset purchase $x^{c}$ and their realization of the date-2 shock $\varepsilon_{2}$. For these banks, the threshold $\widetilde{\varepsilon}_{2}\left(\varepsilon_{1}, x^{c}\right)$ is equal to $\underline{\varepsilon}$ for all $x^{c} \in\left[-\varepsilon_{1}, 1 / \pi_{1}\right]$. Banks with low realizations of $\varepsilon_{1}$ will fail for high values of $x^{c}$ and a sufficiently low value of the date-2 shock. For these banks, the threshold $\widetilde{\varepsilon}_{2}\left(\varepsilon_{1}, x^{c}\right)$ exceeds $\underline{\varepsilon}$, for high $x^{c}$.

From (9), we have that $\widetilde{\varepsilon}_{2}\left(\varepsilon_{1}, x^{c}\right)$ is a decreasing function of $\varepsilon_{1}$ for fixed $x^{c}$. Therefore if $\widetilde{\varepsilon}_{2}\left(\varepsilon_{1}^{\prime}, x^{c}\right)=\underline{\varepsilon}$ for some value $\varepsilon_{1}^{\prime}$ of $\varepsilon_{1}$, then $\widetilde{\varepsilon}_{2}\left(\varepsilon_{1}, x^{c}\right)=\underline{\varepsilon}$ for all $\varepsilon_{1} \geq \varepsilon_{1}^{\prime}$, at that value of $x^{c}$. Define $\widehat{\varepsilon}_{1}$ as the lowest value of $\varepsilon_{1}$ such that commercial banks with $\varepsilon_{1} \geq \widehat{\varepsilon}_{1}$ will not fail at date 2 for any admissible $x^{c}$. For these banks, we have $\widetilde{\varepsilon}_{2}\left(\varepsilon_{1}, x^{c}\right)=\underline{\varepsilon}$ for all $x^{c} \in\left[-\varepsilon_{1}, 1 / \pi_{1}\right]$. Banks with $\varepsilon_{1}<\widehat{\varepsilon}_{1}$ have a positive probability of failing at date 2, for some admissible $x^{c}$. The following lemma indicates that banks' optimal investment behavior depends on whether $\varepsilon_{1}$ is higher or lower than $\widehat{\varepsilon}_{1}$ :

Lemma 2 All banks with values of $\varepsilon_{1}$ high enough to imply that they will not fail under any investment behavior (those with $\varepsilon_{1} \geq \widehat{\varepsilon}_{1}$ ) are indifferent as to how much to trade, and in which direction. Banks with low values of $\varepsilon_{1}$ (those with $\varepsilon_{1}<\widehat{\varepsilon}_{1}$ ) will buy 
$1 / \pi_{1}$ units of the risky asset-the maximum amount allowed by their endowment of the riskless asset.

The proof follows. Date-1 equity for commercial banks is given by

$$
\begin{aligned}
e_{1}^{c}\left(\varepsilon_{1}, d\right)= & \max _{x^{c} \in\left[-\varepsilon_{1}, 1 / \pi_{1}\right]}\left[\frac{\bar{\varepsilon}-\widetilde{\varepsilon}_{2}\left(\varepsilon_{1}, x^{c}\right)}{\bar{\varepsilon}-\underline{\varepsilon}}\right] \\
& {\left[\left(\frac{\bar{\varepsilon}+\widetilde{\varepsilon}_{2}\left(\varepsilon_{1}, x^{c}\right)}{2}\right)\left(\varepsilon_{1}+x^{c}\right)+1-\pi_{1} x^{c}-d\right] . }
\end{aligned}
$$

The first term on the right hand side is the probability of solvency, and the second term is the expected value of date- 2 equity conditional on solvency. It follows immediately that for banks that do not fail (those with $\varepsilon_{1} \geq \widehat{\varepsilon}_{1}$ ) equity is given by

$$
e_{1}^{c}\left(\varepsilon_{1}, d\right)=\pi_{1} \varepsilon_{1}+1-d
$$

which is derived by substituting $\widetilde{\varepsilon}_{2}\left(\varepsilon_{1}, x^{c}\right)=\underline{\varepsilon}$ in (10) and using $\pi_{1}=(\underline{\varepsilon}+\bar{\varepsilon}) / 2$. That $x^{c}$ drops out of this expression reflects the fact that banks with no prospect of receiving a transfer from the insurer are indifferent between all admissible values of $x^{c}$. The intuition for this finding is the same as in Region I: banks that will not fail have no incentive to trade at date 1 , so they value assets in proportion to their date- 2 payoffs.

Now consider banks for which $\varepsilon_{1}<\widehat{\varepsilon}_{1}$. For low values of $x^{c}$ these banks are certain to remain solvent, so date-1 equity does not depend on $x^{c}$. However, for $x^{c}$ above a threshold (that depends on $\varepsilon_{1}$ ) these banks may fail, in which case the direct payoff of the bank's portfolio is augmented by an insurance transfer. In this region the argument of the maximum function in (10) is a strictly increasing function of $x^{c}$. It follows that these banks maximize date- 1 equity by buying as much of the risky asset as they can: $x^{c}=1 / \pi_{1}$.

The date- 1 market for the risky asset clears at the price that prevailed in the absence of deposit insurance, $\pi_{1}=(\underline{\varepsilon}+\bar{\varepsilon}) / 2$, because aggregate net supply of the risky asset by high- $\varepsilon_{1}$ banks is enough to meet aggregate demand for the risky asset by low- $\varepsilon_{1}$ banks. Formally, we have

$$
\int_{\underline{\varepsilon}}^{\widehat{\varepsilon}_{1}} 1 / \pi_{1} d \varepsilon_{1} \leq \int_{\widehat{\varepsilon}_{1}}^{\bar{\varepsilon}} \varepsilon_{1} d \varepsilon_{1},
$$

by the definition of Region II. The threshold $\widehat{\varepsilon}_{1}$ is the solution to $\underline{\varepsilon}\left(\widehat{\varepsilon}_{1}+2 /(\underline{\varepsilon}+\bar{\varepsilon})\right)=d$.

Let $p_{1}^{c}\left(\varepsilon_{1}\right)$ and $q_{1}^{c}\left(\varepsilon_{1}\right)$ denote the unit values of the risky and the riskless assets at date 1 , relative to date- 2 consumption, for a commercial bank with date-1 shock $\varepsilon_{1}$. We have $p_{1}^{c}\left(\varepsilon_{1}\right) / q_{1}^{c}\left(\varepsilon_{1}\right)=\pi_{1}$ for all $\varepsilon_{1}$, due to the fact that commercial banks can trade the risky asset for the riskless asset, or vice versa, at price $\pi_{1}$. The unit values of assets are calculated from bank balance sheet identities, shown in Tables 1, 2 and 3. For commercial banks with $\varepsilon_{1} \geq \widehat{\varepsilon}_{1}$ the unit value of the risky asset is $p_{1}^{c}\left(\varepsilon_{1}\right)=$ $(\underline{\varepsilon}+\bar{\varepsilon}) / 2=\pi_{1}$, which is obtained by substituting (11) in the date-1 bank balance sheet, interpreted as an identity in $\varepsilon_{1}$ and $x^{c}$. Here $\pi_{1}$ equals the expected value of 
Table 1 Commercial bank balance sheets at date 0

\begin{tabular}{ll}
\hline Assets & Liabilities \\
\hline$V^{c}$ (risky + riskless asset) & $d$ (deposits) \\
& $e_{0}^{c}=V^{c}-d$ (equity) \\
\hline
\end{tabular}

Table 2 Commercial bank balance sheet at date 1 after portfolio adjustments

\begin{tabular}{ll}
\hline Assets & Liabilities \\
\hline$p_{1}^{c}\left(\varepsilon_{1}\right)\left(\varepsilon_{1}+x^{c}\right)$ (risky asset) & $d$ (deposits) \\
$q_{1}^{c}\left(\varepsilon_{1}\right)\left(1-\pi_{1} x^{c}\right)$ (riskless asset) & $e_{1}^{c}\left(\varepsilon_{1}, x^{c}\right)=\left(\varepsilon_{1}+x^{c}\right) p_{1}^{c}\left(\varepsilon_{1}\right)+q_{1}^{c}\left(\varepsilon_{1}\right)\left(1-\pi_{1} x^{c}\right)-d$ \\
& (equity) \\
\hline
\end{tabular}

The function $p_{1}^{c}\left(\varepsilon_{1}\right)$ gives the date 1 unit value of the risky asset for a bank that gets the shock $\varepsilon_{1}$ and buys or sells $x^{c}$ units of the risky asset; the function $q_{1}^{c}\left(\varepsilon_{1}\right)$ does the same for the riskless asset. The variable $\pi_{1}$ denotes the price of the risky asset, relative to the riskless asset

Table 3 Commercial bank balance sheet at date 2, under deposit insurance financed entirely by lumpsum taxes

\begin{tabular}{ll}
\hline Assets & Liabilities \\
\hline$\left(\varepsilon_{1}+x^{c}\right) \varepsilon_{2}$ (risky asset) & $d$ (deposits) \\
$1-\pi_{1} x^{c}$ (riskless asset) & \\
$\max \left[-\left\{\left(\varepsilon_{1}+x^{c}\right) \varepsilon_{2}+1-\pi_{1} x^{c}-d\right\}, 0\right]$ (insurance payment) & $e_{2}^{c}=\max \left[\left(\varepsilon_{1}+x^{c}\right) \varepsilon_{2}+1-\pi_{1} x^{c}-d, 0\right]$ (equity)
\end{tabular}

holding the risky asset to date 2 or, equivalently, the proceeds from selling it at date 1. The value of the riskless asset is $q_{1}^{c}\left(\varepsilon_{1}\right)=1$.

For commercial banks with $\varepsilon_{1}<\widehat{\varepsilon}_{1}$ the unit value of the risky asset $p_{1}^{c}\left(\varepsilon_{1}\right)$ strictly exceeds $(\underline{\varepsilon}+\bar{\varepsilon}) / 2$, the value justified by its direct payoff (meaning its payoff excluding the component representing the present value of a transfer from the insurer in the event of failure). The difference $p_{1}^{c}\left(\varepsilon_{1}\right)-(\underline{\varepsilon}+\bar{\varepsilon}) / 2$ reflects the expected value of the transfer from the insurance fund. Similarly, the value of the riskless asset strictly exceeds that justified by its direct payoff, reflecting the fact that a commercial bank with low $\varepsilon_{1}$ does strictly better (in expectation) to sell the riskless asset and buy the risky asset than to hold the riskless asset to maturity.

We turn now from date-1 unit values of assets held by commercial banks to those at date 0 . As noted earlier, risky and riskless assets do not have well-defined distinct unit values at date 0 . However, the unit value (again, relative to date- 2 consumption) at date 0 of the endowment held by a commercial bank is well defined. It equals

$$
\mathbb{E}_{0}\left[\varepsilon_{1} p_{1}^{c}\left(\varepsilon_{1}\right)+q_{1}^{c}\left(\varepsilon_{1}\right)\right]>(\underline{\varepsilon}+\bar{\varepsilon})^{2} / 4+1 .
$$

That the date-0 unit value of the composite commodity strictly exceeds the sum of expected date- 2 direct payoffs reflects the fact that in Region II the date-1 unit value of assets strictly exceeds expected direct payoffs when $\varepsilon_{1}<\widehat{\varepsilon}_{1}$. 
Higher values of $d$ result in higher $\widehat{\varepsilon}_{1}$, implying that more commercial banks run the risk of failure. Thus more commercial banks strictly prefer to buy the risky asset at its equilibrium price, and fewer commercial banks are indifferent as to whether to sell or not. At a borderline value of $d$, risky-asset demand equals supply at the equilibrium price $\pi_{1}=(\underline{\varepsilon}+\bar{\varepsilon}) / 2$. We label that value of $d$ as $d^{I I-I I I}$. The expression for $d^{I I-I I I}$ in Proposition 2 is obtained by noting that at $d=d^{I I-I I I}(12)$ is satisfied as an equality. Performing the integration, solving the resulting quadratic equation and substituting the resulting expression for $\widehat{\varepsilon}_{1}$ in $d=\left(\widehat{\varepsilon}_{1}+1 / \pi_{1}\right) \underline{\varepsilon}$, which states that a bank with $\varepsilon_{1}=\widehat{\varepsilon}_{1}$ that takes maximal risk has assets that are just sufficient for full payment of deposits under the worst possible date- 2 productivity shock, we obtain the stated expression for $d^{I I-I I I}$.

Derivation of Region III If $d$ exceeds the borderline value $d^{I I-I I I}$, commercial banks buying the risky asset demand more of the asset than is available at the price $(\underline{\varepsilon}+\bar{\varepsilon}) / 2$ from the selling banks. In that case the date-1 equilibrium relative price of the risky asset must increase to a level above $(\underline{\varepsilon}+\bar{\varepsilon}) / 2$. We label such values of $d$ as Region III. The following lemma summarizes date- 1 asset trades by commercial banks in Region III.

Lemma 3 In Region III commercial banks with low values of $\varepsilon_{1}$ buy $1 / \pi_{1}$ units of the risky asset. Banks with high values of $\varepsilon_{1}$ strictly prefer to sell their entire holdings of the risky asset, $x^{c}=-\varepsilon_{1}$, in contrast to being indifferent about selling as in Region II. Equilibrium $\pi_{1}$ equates demand and supply.

The equilibrium in Region III is similar to that in Region II except that $\pi_{1}$ is higher than the expected payoff of the risky asset, $(\underline{\varepsilon}+\bar{\varepsilon}) / 2$. Banks with low values of $\varepsilon_{1}$ strictly prefer to buy the risky asset, as in Region II. Commercial banks with high $\varepsilon_{1}$ have lower risk of failing for any value of $x^{c}$, implying that they are less interested in offloading the downside of $\varepsilon_{2}$. For these banks $\pi_{1}$ exceeds the expected date-2 payoff of the risky asset, so they choose to sell all their risky assets, resulting in a zero risk of failure.

The boundary $\widehat{\varepsilon}_{1}$ between the $\varepsilon_{1}$ realizations of commercial banks that buy the risky asset $\left(\varepsilon_{1}<\widehat{\varepsilon}_{1}\right)$ and those that sell it $\left(\varepsilon_{1} \geq \widehat{\varepsilon}_{1}\right)$ is the value of $\varepsilon_{1}$ such that the equity takes on the same value whether the bank buys or sells the risky asset. Evaluating the objective function in (10) at $x^{c}=1 / \pi_{1}$ and setting the resulting expression equal to (11) gives an expression for $\widehat{\varepsilon}_{1}$ as a decreasing function of $\pi_{1}$. A second equation relating $\pi_{1}$ and $\widehat{\varepsilon}_{1}$ comes from the fact that the demand and supply of the risky asset can be written as functions of $\pi_{1}$ and $\varepsilon_{1}$. When (12) holds with equality, aggregate demand for the risky asset equals aggregate supply and we have

$$
\frac{\left(\widehat{\varepsilon}_{1}-\underline{\varepsilon}\right)}{\pi_{1}}=\frac{\bar{\varepsilon}^{2}-\widehat{\varepsilon}_{1}^{2}}{2},
$$

which defines $\widehat{\varepsilon}_{1}$ as an increasing function of $\pi_{1}$. We thus have two functions giving $\widehat{\varepsilon}_{1}$ as a function of $\pi_{1}$, one increasing and one decreasing. Equilibrium occurs at the intersection of these functions. 
Values of risky and riskless assets in Region III are calculated as in Region II. As before, commercial banks with low values of $\varepsilon_{1}$ impute values to both assets strictly higher than their direct date-2 payoffs justify. The lower any commercial bank's realization of $\varepsilon_{1}$ is, the higher is the value imputed to both assets (although, of course, the ratio of these valuations is $\pi_{1}$ for all commercial banks). Commercial banks with $\varepsilon_{1}>\widehat{\varepsilon}_{1}$ impute value $p_{1}^{c}\left(\varepsilon_{1}\right)=\pi_{1}$ to the risky asset because they can sell additional units at that price. This valuation strictly exceeds the direct expected payoff on the risky asset, contrary to the case in Region II. They impute the same value to the riskless asset as its payoff justifies, $q^{c}\left(\varepsilon_{1}\right)=1$.

The upper bound of Region III is the level of $d$ such that the commercial bank with the lowest realization of $\varepsilon_{1}$ (which therefore buys $1 / \pi_{1}$ units of the risky asset at date 1) just avoids failure at the highest realization of $\varepsilon_{2}$. We denote this upper bound for Region III by $d^{*} \equiv\left(\underline{\varepsilon}+1 / \pi_{1}\right) \bar{\varepsilon}$. As discussed above, allowing deposit levels greater than $d^{*}$ makes the equilibrium indeterminate.

General equilibrium The final step of the analysis consists of replacing the assumption that $d$ is specified to equal some arbitrary number in the interval $\left[0, d^{*}\right]$ with the specification that banks set $d$ to maximize expected date- 2 consumption of agents, equal to the sum of deposits plus date-0 equity, less the lump-sum tax. Restricting attention to equilibria in which all agents choose the same $d$, which is without loss of generality in this section (but not so in general, as we will see below), the task is to find the value(s) of $d$ such that an individual agent will not deviate from the value chosen by other agents.

Proposition 3 When deposit insurance is financed via lump-sum taxes, all agents create commercial banks. It is optimal for all commercial banks to set $d=d^{*}$. In equilibrium, assets are overvalued relative to the no deposit insurance case.

Proposition 3 reflects the fact that maximizing expected date-2 consumption involves maximizing the expected transfer from the deposit insurer. It follows that in equilibrium agents direct their assets exclusively to commercial banks, where they have some prospect of receiving a transfer from the insurer. (Agents who directed their assets to shadow banks instead would pay the same lump-sum tax as everyone else, but would not benefit from the insurance transfer.) For commercial banks, setting $d$ equal to $d^{*}$ is a dominant strategy against any value of $d$ chosen by other banks. Therefore $d=d^{*}$ is an equilibrium in dominant strategies: commercial banks set deposits at the highest level permitted by the insurer. ${ }^{15}$

\subsection{Deposit-based premia}

In the United States banks have historically paid insurance premia to the Federal Deposit Insurance Corporation based either on the amount of deposits that are insured

\footnotetext{
15 The observation that levered banks value deposit insurance more highly than unlevered banks, with the corollary that banks' motivation for adopting highly levered asset structures is precisely to maximize the value of deposit insurance, has been made in partial equilibrium settings before. See Keeley and Furlong (1990), for example.
} 
or on the bank's assets. In this section we alter the model by assuming that the insurer charges commercial banks a sum equal to bank deposits multiplied by an insurance premium $\delta$ (for "deposits"). Commercial banks take $\delta$ as given.

Definition 1 The deposit insurance program is revenue neutral when $\delta$ is such that the revenue from the insurance premium alone equals the total transfer to failed banks. We distinguish two types of revenue neutrality:

1. Nontrivial revenue neutrality The total revenue and total transfers are equal and nonzero.

2. Trivial revenue neutrality The total revenue and total transfers are both zero.

If the total transfer to failed banks exceeds revenue from insurance premia the shortfall is made up by a lump-sum tax. In that case, the expected insurance benefit exceeds the insurance premium and the deposit insurance program is revenue favorable to commercial banks. The dependence of equilibrium values of variables on $\delta$ necessitates changes in notation. The corresponding modifications also apply in the following section.

The equilibria under deposit-based premia are generated by setting $j=\delta d$ in (1). Banks that cannot pay the insurance premium at date 2 do not survive. Therefore the upper bound on deposits depends on the insurance premium rate $\delta$, so we denote it as $d^{*}(\delta)$. It is given by

$$
d^{*}(\delta)=\frac{\bar{\varepsilon}\left(\underline{\varepsilon}+1 / \pi_{1}(\delta)\right)}{1+\delta},
$$

reflecting the condition that deposits $d^{*}(\delta)$ plus the premium $\delta d^{*}(\delta)$ equals $\bar{\varepsilon}(\underline{\varepsilon}+$ $\left.1 / \pi_{1}(\delta)\right)$. As the equation above indicates, and as we will see in what follows, the equilibrium date-1 relative price of the risky asset depends on $\delta$.

While it is easy to modify the model to allow for deposit-based insurance premia, it turns out that the equilibria under deposit-based premia are different from those under lump-sum taxes. The following proposition presents the main finding of this section.

Proposition 4 There exist premium levels $\underline{\delta}$ and $\bar{\delta}$, with $\underline{\delta}<\bar{\delta}$, such that equilibria with deposit-based insurance premia exhibit the following properties:

1. Revenue neutrality Deposit insurance is strictly revenue-favorable to commercial banks when $\delta<\bar{\delta}$, nontrivially revenue neutral when $\delta=\bar{\delta}$ and trivially revenue neutral when $\delta>\bar{\delta}$.

2. Coexistence All agents create commercial banks when $\delta \leq \underline{\delta}$, and all agents create shadow banks when $\delta>\bar{\delta}$. Agents are indifferent between allocating their endowment to commercial banks versus shadow banks when $\underline{\delta} \leq \delta \leq \bar{\delta}$. For $\underline{\delta}<\delta<\bar{\delta}$ a nonzero measure of agents create commercial banks and a nonzero measure create shadow banks. For $\delta=\bar{\delta}$ there exists a continuum of equilibria; in one of these all agents form shadow banks, and in the others a nonzero measure of agents create commercial banks and a nonzero measure of agents create shadow banks.

3. Bank portfolios When commercial banks and shadow banks coexist, shadow banks sell their holdings of the risky asset to commercial banks at date 1. 
4. Asset prices Asset prices are distorted when $\delta<\bar{\delta}$ and undistorted when $\delta \geq \bar{\delta}$.

In the rest of this section we characterize equilibria for different values of $\delta$ and provide intuition for Proposition 4 above. First, if $\delta$ equals zero we are back to the case analyzed above in which subsidized deposit insurance is financed entirely via lump-sum taxes. Suppose now that $\delta$ is set at a low level. In that case most of the revenue required to finance the transfer to depositors at failed commercial banks is raised by lump-sum taxes. Not surprisingly, the equilibrium in this case is the same as that which obtains when the entire cost of deposit insurance is financed by a lump-sum tax, as analyzed above. All agents allocate their assets to commercial banks, since to do otherwise involves forgoing the possible payment from the deposit insurer. For the same reason, commercial banks will set deposits equal to $d^{*}(\delta)$, the maximum level permitted by the insurer. For low levels of $\delta$, the equilibrium date- 0 value of the composite good exceeds its expected direct payoff, reflecting the fact that the expected insurance transfer is capitalized into the value of the composite good. For the rest of the section, we simplify the exposition and use the term commercial banks to mean commercial banks with $d=d^{*}(\delta) .^{16}$

At higher levels of $\delta$ the expected payoff from starting commercial banks is decreased. Shadow banks do not pay the insurance premium and therefore become less unattractive investments relative to commercial banks. At a certain value of $\delta$, which we label $\underline{\delta}$, an agent's expected date- 2 consumption from starting a shadow bank equals his expected consumption from starting a commercial bank. Accordingly, agents are indifferent between allocating their endowment to either bank. For $\delta=\underline{\delta}$ deposit insurance is strictly revenue-favorable to commercial banks: the expected insurance payment to commercial banks strictly exceeds the insurance premium paid by these banks.

For $\delta=\underline{\delta}$ all agents form commercial banks (this, of course, is consistent with individual agents being indifferent as to whether to start a commercial bank or a shadow bank). When $\delta$ strictly exceeds $\underline{\delta}$ individual agents are still indifferent about whether to start a commercial bank or shadow bank. However, it is no longer true that all agents start commercial banks: a strictly positive measure of agents allocate assets to shadow banks at date 0. Unlike in Sect. 3.1, shadow banks here do not hold the risky asset to maturity. Instead, it is optimal for shadow banks to sell their entire holding of the risky asset to commercial banks at date 1. Doing so attains a higher expected payoff than holding to maturity because the risky asset trades at a premium at date 1 , and shadow banks cannot benefit from an insurance payoff. This ability to sell risky assets at a price that exceeds their expected payoff allows shadow banks to benefit indirectly from deposit insurance that directly subsidizes commercial banks. The expected date2 consumption of an agent who creates a shadow bank is $V^{s}(\delta)=\pi_{1}(\delta)(\underline{\varepsilon}+\bar{\varepsilon}) / 2+1$. For each level of $\delta$ the measure of agents starting commercial banks is determined as part of the equilibrium as a decreasing (and strictly decreasing for $\delta>\underline{\delta}$ ) continuous function of $\delta$. Thus when $\delta$ exceeds $\underline{\delta}$ by a small amount some agents will start shadow

\footnotetext{
16 With deposit-based premia, there is no distinction between nominal commercial banks (those with $d=0$ ) and shadow banks: both institutions avoid the direct benefits and costs of deposit insurance. We do not distinguish between the two types of banks and use the term shadow banks to refer to either type of institution.
} 
banks, but the majority will start commercial banks. For higher values of $\delta$ a majority of agents will start shadow banks.

The result that for $\delta>\underline{\delta}$ some agents form shadow banks that sell off their holding of the risky asset at date 1 is unexpected. The reason for the date- 1 sale of the risky asset is that the demand for risky assets comes from commercial banks with low realizations of $\varepsilon_{1}$. These banks are willing to pay a high price for the risky asset because they are likely to fail, and therefore to benefit from a transfer from the deposit insurer. At date 0 these banks do not yet know that they will be in danger of failing, so they would not pay a high price for the risky asset. Thus the transfer of the risky asset can only come at date 1 , after the realizations of $\varepsilon_{1}$.

At higher levels of $\delta, \pi_{1}(\delta)$ decreases toward the expected date-2 direct payoff of the risky asset, relative to the riskless asset. This fact implies that a sufficiently high value of $\delta$, labeled $\bar{\delta}$, will result in an equilibrium in which the prices of risky and riskless assets equal (that is, no longer exceed) their respective expected direct payoffs. At $\delta=\bar{\delta}$ the deposit insurance program does not favor either commercial or shadow banks: selling the risky asset at date 1 does not directly benefit shadow banks because for $\delta=\bar{\delta}$ deposit insurance does not distort asset prices in favor of risky assets. Starting commercial banks is not advantageous either because the expected gain from offloading the lower tail of the return distribution to the insurer is exactly offset by the expected insurance premium.

Deposit insurance is nontrivially revenue neutral at $\delta=\bar{\delta}$. We have seen that for $\delta<\bar{\delta}$ deposit insurance is revenue-favorable to commercial banks (that is, it entails a subsidy financed by lump-sum taxes). For $\delta>\bar{\delta}$ deposit insurance is trivially revenue neutral: all agents avoid participating in the deposit insurance program by creating shadow banks, so the insurer's revenue and expenditure both equal zero. We see that nontrivial revenue neutrality is a knife-edge case that divides revenue-nonneutrality $(\delta<\bar{\delta})$ from trivial revenue neutrality $(\delta>\bar{\delta})$.

\subsection{Risky-asset-based premia}

Many analysts of banking recommend replacing deposit insurance premia based on deposit levels with premia based on asset risk: banks would be required to pay higher insurance premia to the extent that they hold more risky assets. In the United States the Federal Deposit Insurance Corporation is now moving in that direction. In this section we adapt the model so that insurance premia are based on holdings of the risky asset rather than deposits. We assume that commercial banks pay premia proportional to their after-trade date 1 holdings of the risky asset, with the factor of proportionality $\rho$ (for "risky"). Here $\rho$ is the same at all banks and does not depend on the magnitude of deposit liabilities. As with the deposit-based premia of the preceding section, any shortfalls in the insurance fund are made up by a lump-sum tax.

The equilibria in this section are generated by setting $j=\rho\left(\varepsilon_{1}+x\right)$ in (1). It follows that commercial banks that sell their entire holding of the risky asset, $x=-\varepsilon_{1}$, do not pay an insurance premium. As with deposit-based premia of the preceding section, the maximum deposit level at commercial banks permitted by the insurer depends on 
$\rho$. This level is given by

$$
d^{*}(\rho)=\left(\underline{\varepsilon}+1 / \pi_{1}(\rho)\right)(\bar{\varepsilon}-\rho) \text {. }
$$

As in the preceding section, we omit the details of the analysis. The following proposition presents the main finding of this section.

Proposition 5 There exist premium levels $\rho$ and $\bar{\rho}$, with $\rho<\bar{\rho}$, such that equilibria with risky-asset-based insurance premia exhibit the following properties:

1. Revenue neutrality Deposit insurance is strictly revenue-favorable to commercial banks when $\rho<\bar{\rho}$ and trivially revenue neutral when $\rho \geq \bar{\rho}$. There is no equilibrium in which deposit insurance is nontrivially revenue neutral.

2. Coexistence All agents create commercial banks when $\rho \leq \underline{\rho}$, and all agents create shadow banks when $\rho \geq \bar{\rho}$. Agents are indifferent between allocating their endowment to commercial banks versus shadow banks when $\rho \leq \rho \leq \bar{\rho}$. For $\underline{\rho}<\rho<\bar{\rho}$ a nonzero measure of agents create commercial banks and a nonzero measure create shadow banks.

3. Bank portfolios When commercial banks and shadow banks coexist, commercial banks sell their holdings of the risky asset to shadow banks at date 1.

4. Asset prices Asset prices are distorted when $\rho<\bar{\rho}$ and undistorted when $\rho \geq \bar{\rho}$.

In what follows we will characterize the equilibria for different values of $\rho$ and provide intuition for Proposition 5. At the end of the section, we compare properties of revenue-neutral equilibria with deposit-based premia to those with risky-asset-based premia. As in the previous section, we simplify the exposition in this section and use the term commercial banks to refer to commercial banks with deposits equals to $d^{*}(\rho) .{ }^{17}$

The equilibrium when $\rho$ equals zero reduces to the lump-sum case: all agents form commercial banks in order to take maximum advantage of the favorable deposit insurance program. Suppose that $\rho$ is set at a value slightly higher than zero. Doing so implies a higher cost of holding risky assets, thereby inducing some commercial banks with intermediate realizations of $\varepsilon_{1}$ who otherwise would be buyers of the risky asset to sell their holding at date 1 . As a consequence, aggregate supply of the risky asset exceeds aggregate demand at the date- 1 relative price that prevails for $\rho=0$. It follows that, at the higher value of $\rho$, the date- 1 relative price of the risky asset must decline for markets to clear. The date- 0 expected payoff from starting a commercial bank decreases when $\rho$ is increased from zero to the higher value. As $\rho$ is set at still higher values, $\pi_{1}(\rho)$ is lower, further decreasing the superiority of creating commercial banks over creating shadow banks at date 0 . Eventually $\pi_{1}(\rho)$ drops below the relative price associated with the expected date- 2 payoffs of risky versus riskless assets. ${ }^{18}$ At a still

\footnotetext{
17 Nominal commercial banks cannot avoid the risky-asset-based insurance premia. Therefore, in this section, shadow banks dominate nominal commercial banks.

18 It is obvious that such a drop must come eventually, since at some level of $\rho$ the premium cost of deposit insurance will exceed the expected benefit of the bankruptcy transfer. It is noteworthy, and somewhat counterintuitive, that this drop comes even under levels of $\rho$ low enough that all banks choose to create commercial banks at date 0 .
} 
higher value of $\rho$, which we label $\rho$, the date- 1 relative price of the risky asset is so far below its expected direct payoff that an individual agent's payoff from allocating his assets to a shadow bank that buys the risky asset at date 1 is the same as his payoff from starting a commercial bank. It follows that for $\rho=\rho$ individual agents at date 0 are indifferent between creating commercial banks and creating shadow banks. For $\rho=\rho$ all agents create commercial banks.

When $\rho$ exceeds $\rho$ by a small amount most agents create commercial banks, but others create shadow banks and purchase $1 / \pi_{1}(\rho)$ units of the risky asset at date 1 from commercial banks with high realizations of $\varepsilon_{1}$. The expected payoff from creating commercial banks equals that from creating shadow banks, implying that individual agents are indifferent about whether to turn over their assets to commercial banks or shadow banks. The proportion of agents who choose to form commercial banks is continuous and declining in $\rho$.

Commercial banks are buyers or sellers of the risky asset at date 1 depending on whether their realization of $\varepsilon_{1}$ is below or above $\widehat{\varepsilon}_{1}$. We have that $\pi_{1}(\rho)$ is high-but still lower than the present value of the payoff of the risky asset relative to the riskless asset-when $\rho$ is high, reflecting the fact that high $\rho$ induces many agents to create shadow banks, which are buyers of the risky asset at date 1. Unlike deposit-based premia of the preceding section, the date- 1 relative price of the risky asset is thus a non-monotonic function of the risky-asset-based insurance premium rate.

It is noteworthy that when insurance premia are based on holdings of risky assets (and satisfy $\rho<\rho$ ) shadow banks are buyers of risky assets, rather than being sellers as when premia are based on deposits. This occurs because shadow banks are exempt from insurance premia, and occurs despite the fact that they will not receive a transfer in the event of failure, which by itself would confer a comparative advantage on commercial banks as holders of risky assets. Commercial banks with high realizations of $\varepsilon_{1}$ determine that the insurance premium exceeds the expected insurance transfer, so they sell the risky asset and avoid the insurance premium. For still higher values of $\rho$ all commercial banks except those with very low realizations of $\varepsilon_{1}$ elect to sell the risky asset in order to avoid the insurance premium.

At a sufficiently high value of $\rho$, labeled $\bar{\rho}$, commercial banks with $\varepsilon_{1}>\underline{\varepsilon}$ elect to sell the risky asset. With all risky assets transferred to the shadow banks, the equilibrium date-1 relative price of the risky asset equals the ratio of the direct asset payoffs. At $\bar{\rho}$ the deposit insurance program is overpriced for all commercial banks excepting the banks with $\varepsilon_{1}=\underline{\varepsilon}$ (a set of measure zero), who are indifferent about whether to participate in the deposit insurance program or not.

Risky-asset-based deposit insurance is trivially revenue neutral at $\rho=\bar{\rho}$, and also for $\rho>\bar{\rho}$ : being overpriced, deposit insurance results in all risky assets being held by shadow banks, who do not participate in deposit insurance.

Risky-asset-based versus deposit-based premia Comparing the results of this and the preceding section, it becomes clear that there are strong similarities between the equilibria that result from deposit-based premia and those resulting from risky-assetbased premia, but also one major difference. As for the similarities, in both cases low insurance rates involve a heavy subsidy to commercial banks, and agents respond to the resulting opportunity by allocating assets to commercial banks that set deposit 
levels as high as possible. For insurance premia in the intermediate range- $\underline{\delta}<\delta<\bar{\delta}$ and $\rho<\rho<\bar{\rho}$-some agents form commercial banks and others form shadow banks. Under both insurance regimes shadow banks benefit to the same extent as commercial banks from subsidized deposit insurance. This is so for deposit-based premia because shadow banks sell the risky asset at prices that exceed its expected payoff, while for risky-asset-based premia shadow banks buy the risky asset at prices that are lower than expected payoffs.

The major difference between deposit-based premia and risky-asset-based premia is that in the former case there exist nontrivially revenue-neutral equilibria, while in the latter case there do not. As we have seen, with $\delta=\bar{\delta}$ there exists a continuum of equilibria, each associated with a different measure of agents' creating commercial banks versus shadow banks. These equilibria, being revenue-neutral, result in undistorted asset prices. In contrast, with risky-asset-based premia, commercial banking collapses for $\rho=\bar{\rho}$ : for $\rho \geq \bar{\rho}$ all risky assets are held by shadow banks at date 1 , and asset prices are undistorted. This is an important finding: to the extent that policy-makers want to implement an insurance program that does not induce asset price distortions, but also does not put commercial banks out of business, they must implement deposit-based premia and not risky-asset-based premia.

To understand the difference between equilibria with deposit-based and risky-assetpremia, focus first on the latter case. For $\rho \leq \rho \leq \bar{\rho}$ commercial banks with high realizations of $\varepsilon_{1}$ find that the expected benefit from deposit insurance is lower than the premium, so they sell their risky assets to commercial banks with low realizations of $\varepsilon_{1}$ and to shadow banks, which do not pay insurance premia. For values of $\rho$ close to $\bar{\rho}$ almost all commercial banks are in this class. The fact that almost all commercial banks will be selling their risky assets at date 1 is consistent with market-clearing only if at date 0 almost all agents direct their wealth to shadow banks rather than commercial banks. In the limit $(\rho=\bar{\rho})$ premium revenue for the insurer is zero, and this is consistent with market-clearing and revenue-neutrality because there are no commercial banks.

Under deposit-based premia, in contrast, commercial banks with high realizations of $\varepsilon_{1}$ have no way to avoid paying the insurance premium since they cannot reduce their deposit liabilities at date 1 . Therefore $\delta=\bar{\delta}$ is consistent with an equilibrium in which the insurer collects a nonzero level of premium income. This is consistent with agents being indifferent between starting commercial banks and shadow banks because their expected (at date 0 ) benefit from deposit insurance payouts equals their premium payment. At date 1 commercial banks with low realizations of $\varepsilon_{1}$ view deposit insurance as actuarially favorable, while those with high realizations of $\varepsilon_{1}$ view it as unfavorable.

\section{A numerical example}

We now present a numerical example that helps illustrate the theoretical findings in the preceding sections. Our example will set $\bar{\varepsilon}$ to 2 and $\underline{\varepsilon}$ to 0.5 , implying that the risky asset is equally likely to experience any outcome between a doubling and a halving at date 1 , and similarly at date 2 . 




Fig. 1 Asset prices for various levels of deposits when deposit insurance is financed using lump-sum taxes. In equilibrium, agents set $d$ to its highest admissible value, $d=d^{*}=2.47$. The upper horizontal axis shows how imposing a capital requirement $\kappa$ affects the equilibrium. For a given value of $\kappa$, the corresponding value of $d$ indicates the equilibrium level of deposits

No deposit insurance Consider first the setting in which there is no deposit insurance, discussed in Sect. 3.1. In that case the value of the risky asset is $1.25^{2}=1.56$ at date 0 and 1.25 at date 1 . The riskless asset has price 1 at both dates. Thus the date- 0 value of each agent's endowment is 2.56 .

Lump-sum tax financed insurance Now impose deposit insurance. The equilibrium level $d^{*}$ of $d$ equals 2.47. Figure 1 plots $V^{c}$ and $\pi_{1}$ as functions of $d$ for values of $d$ between 0 and 2.47. The boundaries for the equilibrium regions discussed in Proposition 2 are as follows: $d^{I-I I}=0.65$ and $d^{I I-I I I}=1.16$.

The existence of deposit insurance increases the date- 0 equilibrium price of the composite commodity, consisting of one unit of the risky and one unit the riskless asset, from 2.56 (calculated as $1.56+1$ ) to 2.93. This increase in the value of endowments is exactly offset by the lump-sum tax $t$.

Deposit-based premia Figures $2 \mathrm{a}-\mathrm{d}$ and 3 present the equilibria. The upper boundary value $\underline{\delta}$ for the region where all agents start commercial banks equals 0.10 . As $\delta$ rises from 0.10 to about 0.15 the measure of agents who form commercial banks decreases 


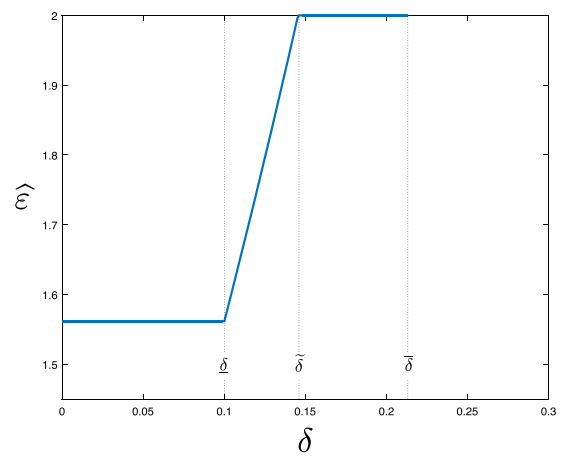

(a) The threshold $\widehat{\varepsilon}_{1}$ is that value of the date- 1 shock $\varepsilon_{1}$ at which commercial banks switch from being buyers $\left(\varepsilon_{1}<\widehat{\varepsilon}_{1}\right)$ to sellers $\left(\varepsilon_{1} \geq \widehat{\varepsilon}_{1}\right)$ of the risky asset.

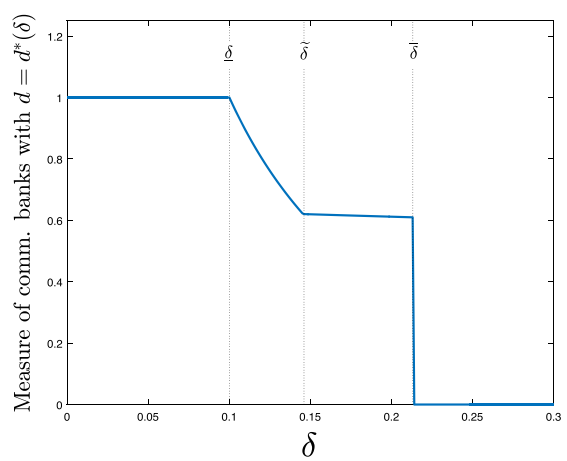

(c) The measure of agents that start commercial banks.

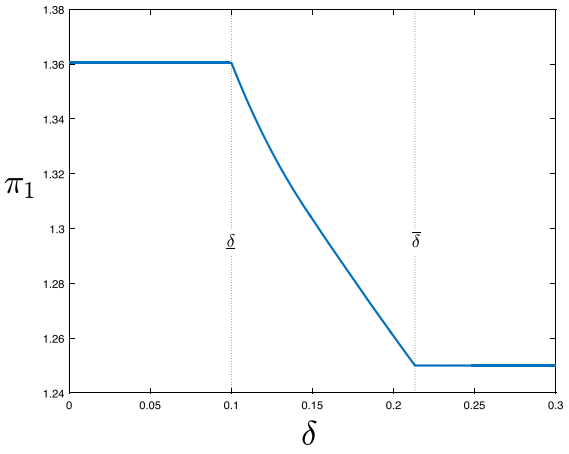

(b) Relative price of the risky asset at date 1 . All agents start commercial banks when $\delta<\underline{\delta}$; shadow banks and commercial banks coexist when $\underline{\delta}<\delta \leq \bar{\delta}$; all agents start shadow banks when $\bar{\delta}>\bar{\delta}$

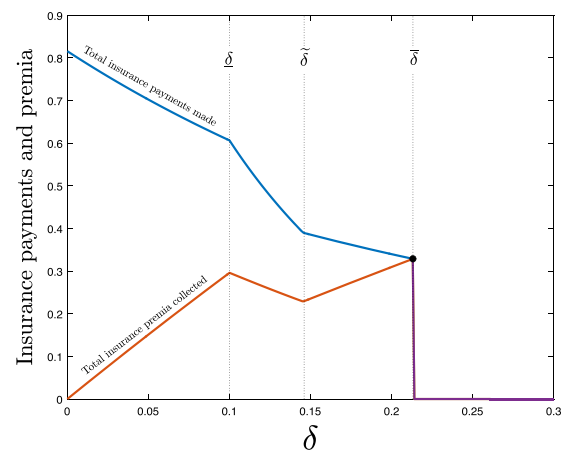

(d) The total insurance premia collected and the total insurance payments made by the insuring agency. Deposit insurance is non-trivially revenue neutral when $\delta=\bar{\delta}$, and trivially so when $\delta>\bar{\delta}$.

Fig. 2 Equilibrium under insurance premia based on deposit levels

from 1 to about 0.6 (Fig. 2c). Correspondingly, the measure of agents who form shadow banks increases from 0 to about 0.4 . As the figure indicates, the measure of commercial banks has a kink at about $\delta \simeq 0.15 \equiv \widetilde{\delta}$. The kink occurs because for $\delta$ less than $\widetilde{\delta}$ an increase in $\delta$ increases aggregate demand for the risky asset by increasing $\widehat{\varepsilon}$ (Fig. 2a); recall that commercial banks with $\varepsilon_{1}<\widehat{\varepsilon}_{1}$ are buyers of the risky asset, while those with $\varepsilon_{1} \geq \widehat{\varepsilon}_{1}$ are sellers. At $\delta=\widetilde{\delta}$ all commercial banks are buyers of the risky asset at date $1, \widehat{\varepsilon}_{1}=\bar{\varepsilon}$. Therefore the effect just described disappears for $\delta>\widetilde{\delta}$. Further increases in $\delta$ result in a much more gradual decrease in the measure of commercial banks (there is still some effect because $\delta$ affects the equilibrium prices of risky and riskless assets, which in turn affect banks' date- 1 trades in assets). For values of $\delta$ greater than $\widetilde{\delta}$ about $60 \%$ of agents start commercial banks that are buyers of the risky asset at date 1 , while the remaining agents start shadow banks that are sellers of the risky asset. 


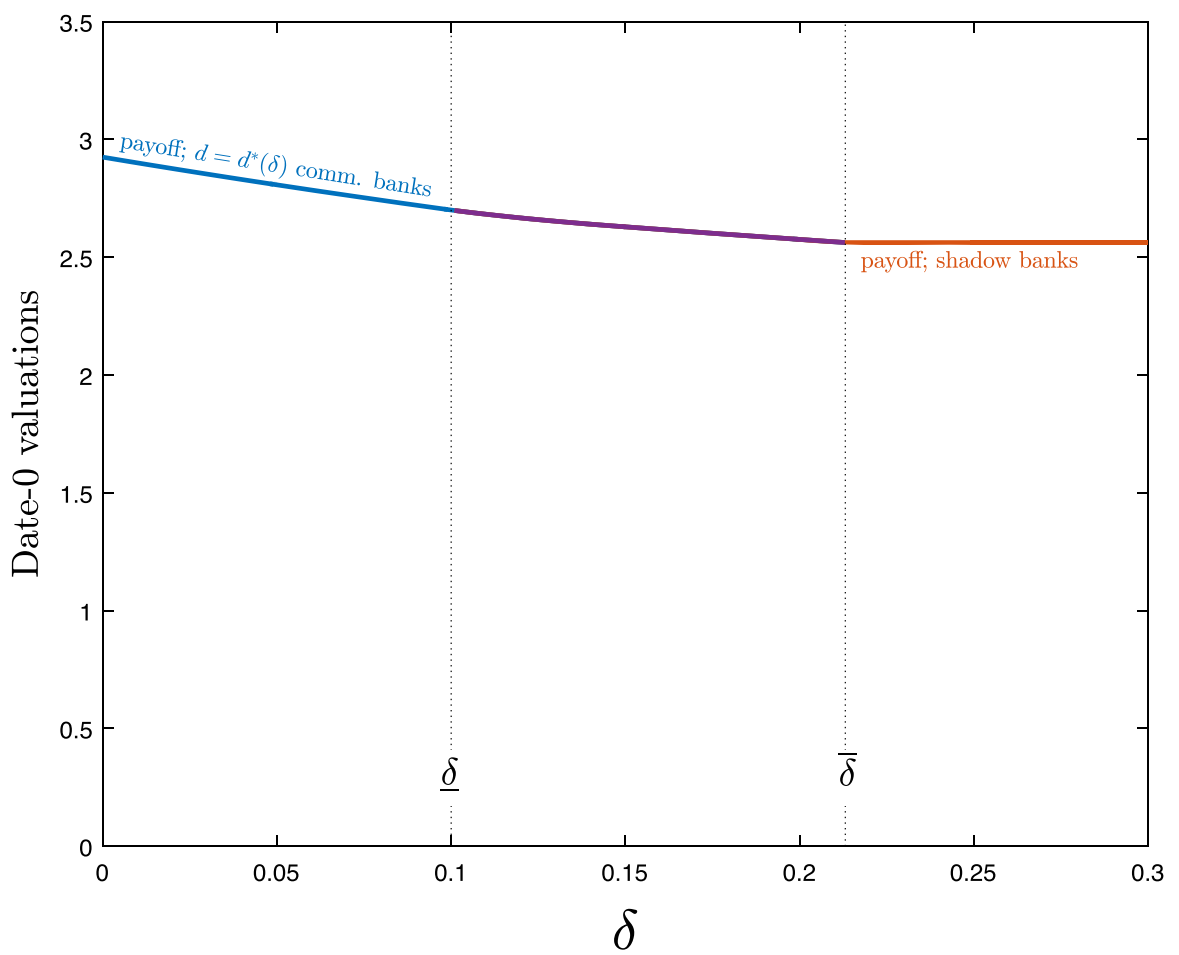

Fig. 3 Date-0 valuation of the endowment by commercial banks $(\delta<\bar{\delta})$ and shadow banks $(\delta>\underline{\delta})$, when insurance premia are based on deposit levels. For $\underline{\delta}<\delta<\bar{\delta}$ both commercial banks and shadow banks are being created. The difference between the value of the payoff line and 2.56 represents the aggregate lump-sum tax

The threshold $\bar{\delta}$ equals 0.21 . Deposit insurance is non-trivially revenue neutral at that value of $\delta$, and trivially so for higher values of $\delta$. Figure $2 \mathrm{~d}$ shows the insurer's expenditures and revenues as functions of $\delta$. At $\delta=\bar{\delta}$ the mapping between $\delta$ and the proportion of commercial banks is multivalued: it ranges from zero to about $60 \%$. The multivalued mapping is a consequence of the fact that, at prevailing market prices, date 1 asset markets clear as long as aggregate demand of the risky asset from commercial banks is less than the net supply of the asset from shadow banks, as it is if fewer than $60 \%$ of agents form commercial banks.

Figure 3 shows equilibrium date- 0 valuations of the composite commodity on the balance sheets of commercial banks and of shadow banks.

Risky-asset-based premia Figures $4 \mathrm{a}-\mathrm{d}$ and 5 present the equilibria. In this example all agents create commercial banks as long as $\rho$ is less than $\rho=0.307$. When $\rho=\rho$, the date- 1 relative price is around 1.15 , which is below the relative expected direct payoff from one unit of the risky asset (see Fig. 4b). When $\rho$ exceeds $\rho$, the measure of commercial banks declines (see Fig. 4c). For example, when $\rho=\overline{0.5}$, only about $50 \%$ of agents create commercial banks. The date- 1 relative price of the risky asset increases with $\rho$-when $\rho=0.5$ the date- 1 price is about 1.23 -reflecting the fact 


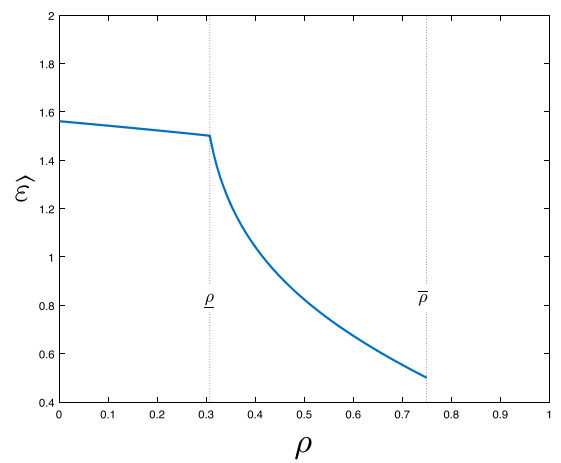

(a) The threshold $\widehat{\varepsilon}_{1}$ is that value of the date- 1 shock $\varepsilon_{1}$ at which commercial banks switch from being buyers $\left(\varepsilon_{1}<\widehat{\varepsilon}_{1}\right)$ to sellers $\left(\varepsilon_{1} \geq \widehat{\varepsilon_{1}}\right)$ of the risky asset.

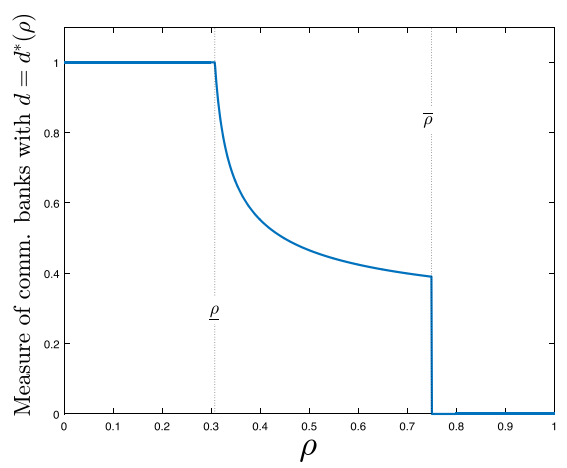

(c) The measure of agents that start commercial banks.

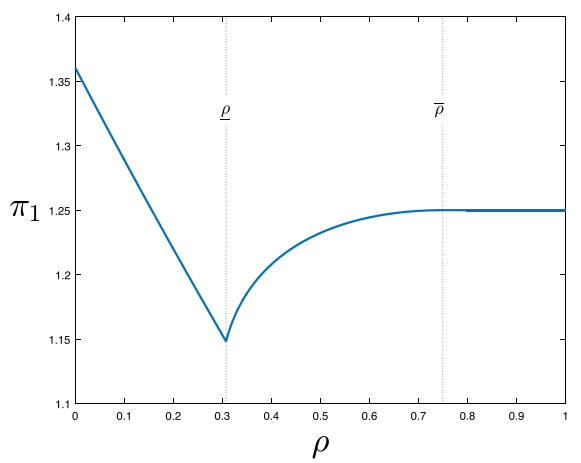

(b) Relative price of the risky asset at date 1 . All agents start commercial banks when $\rho<\underline{\rho}$; shadow banks and commercial banks coexist when $\rho<\rho \leq \bar{\rho}$; all agents start shadow banks or commercial banks that sell their entire holding of the risky asset when $\rho>\bar{\rho}$.

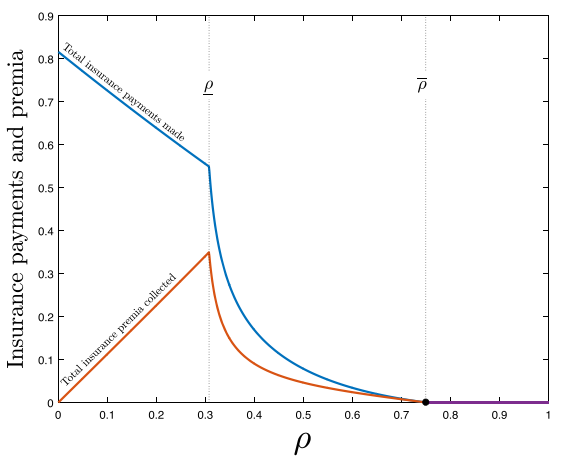

(d) The total insurance premia collected and the total insurance payments made by the insuring agency. Deposit insurance is trivially revenue neutral for all $\rho \geq \bar{\rho}$.

Fig. 4 Equilibrium under insurance premia based on risky-asset holdings

that the shadow banks buy the risky asset at date 1 . The threshold $\bar{\rho}$ equals 0.74 . At that value of $\rho$, the relative price of the risky asset equals 1.25, the relative expected direct payoff from one unit of the risky asset. As with deposit-based insurance premia, the mapping between the risky-asset-based insurance premium rate $\rho$ and the proportion of commercial banks is multivalued at $\bar{\rho}$ : it ranges from about $40 \%$ to 0 .

\section{Capital requirements}

We modify the model presented in Sect. 2 to allow for capital requirements. In practice, capital requirements are usually expressed in terms of a lower bound on bank equity. 


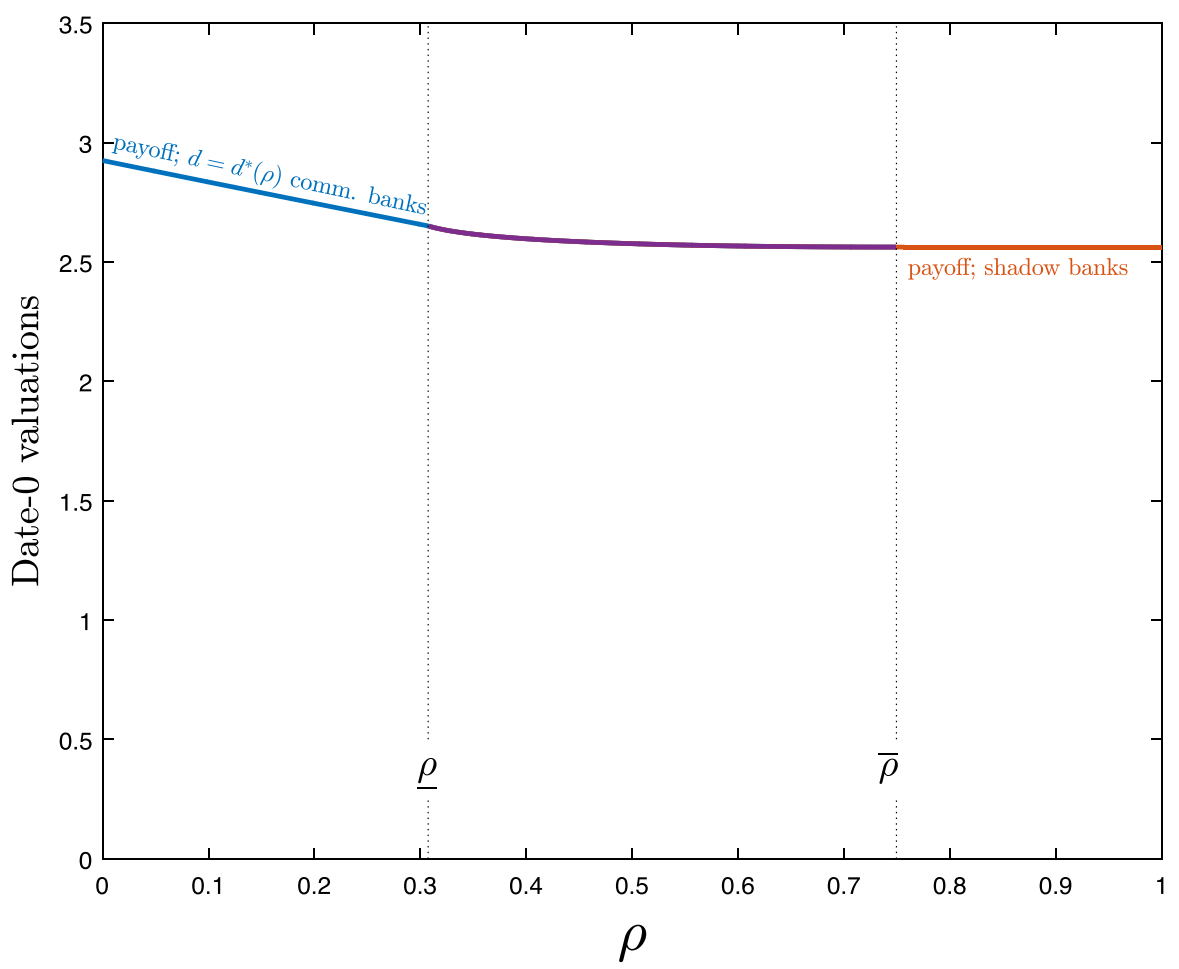

Fig. 5 Date- 0 valuation of the endowment by commercial banks $(\rho<\bar{\rho})$ and shadow banks $(\rho>\rho)$, when insurance premia are based on holdings of the risky asset. Again, for $\underline{\rho}<\rho<\bar{\rho}$, the line is purple because both commercial banks and shadow banks are being created

Here we make use of the bank balance sheet identity and instead express the capital requirement as an upper bound on deposits. We assume that the capital requirement is a reduction in the maximum admissible level of deposits by a proportion $\kappa$ (for "capital"). Thus the analysis of Sect. 3 corresponds to the case $\kappa=0$, and the other extreme, $\kappa=1$, corresponds to a prohibition of deposits, so that commercial banks become identical to shadow banks. The equilibrium with capital requirement $\kappa$ involves only a minor modification of the methods outlined in the earlier sections, so we omit the details. We use the numerical example presented in Sect. 4 to discuss how capital requirements alter the equilibrium of the model for each financing regime. As above, we start with the case of lump-sum taxes and then allow for deposit-based insurance premia and risky-asset-based premia.

Lump-sum taxes We modify the notation to reflect the dependence of equilibrium values of variables on the capital requirement: the upper bound on deposits and the date- 1 relative price of the risky asset are now denoted $d^{*}(\kappa)$ and $\pi_{1}(\kappa)$. We have

$$
d^{*}(\kappa)=\bar{\varepsilon}\left(\underline{\varepsilon}+1 / \pi_{1}(\kappa)\right)(1-\kappa),
$$




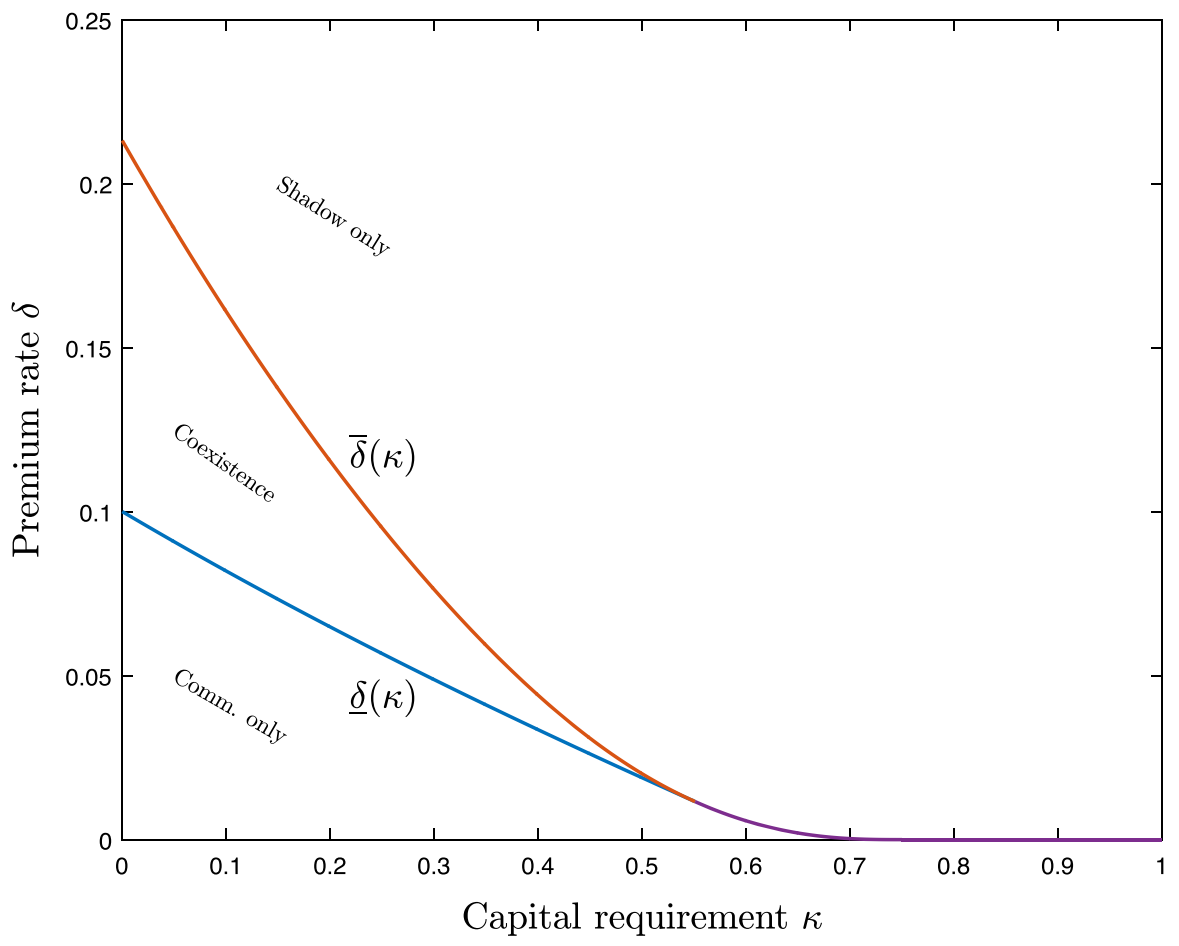

Fig. 6 Equilibrium regions under capital requirements with deposit-based premia. All agents create commercial banks for values of $\delta$ below the $\underline{\delta}(\kappa)$ curve. Commercial and shadow banks coexist between the $\underline{\delta}(\kappa)$ and $\bar{\delta}(\kappa)$ curves. All agents create shadow banks above the $\bar{\delta}(\kappa)$ curve. Agents are indifferent between creating commercial or shadow banks where the two curves meet, $\kappa \geq 0.55$. All breakdowns of banks into commercial and shadow is consistent with equilibrium for those values of $\kappa$. The equilibrium is nontrivially revenue neutral along the $\bar{\delta}(\kappa)$ curve

so that with $\kappa>0$ commercial banks are permitted to issue deposits only up to a proportion $1-\kappa$ of the level that would be permitted in the absence of a capital requirement. As (17) indicates, this bound is modified by altering $\pi_{1}$ to reflect the fact that imposing capital requirements alters the equilibrium relative price of assets.

Figure 1 shows the equilibrium values as the capital requirement increases from 0 to 1 . The figure contain two horizontal axes. The top horizontal axis of the figure shows the capital requirement $\kappa$, while the bottom horizontal axis shows deposit levels at commercial banks $d$. The bottom axis corresponds to the maximal deposit levels $d^{*}(\kappa)$ under the capital requirement $\kappa$.

First, if $\kappa$ equals zero we are back to the equilibrium derived in Sect. 3.2. In the $\kappa=0$ equilibrium, we have $d^{*}(0)=2.47, \pi_{1}(0)=1.36$ and $\widehat{\varepsilon}_{1}(0)=1.56$. Now consider a small increase in the capital requirement, say $\kappa=0.01$. The equilibrium is qualitatively similar to the case with no capital requirements: all agents continue to create commercial banks that issue maximal deposit levels. At the higher value of $\kappa$, the maximal deposit level at each commercial bank is lower than 2.47. As a consequence, a lower proportion of banks will fail, and those banks that do fail require a smaller 


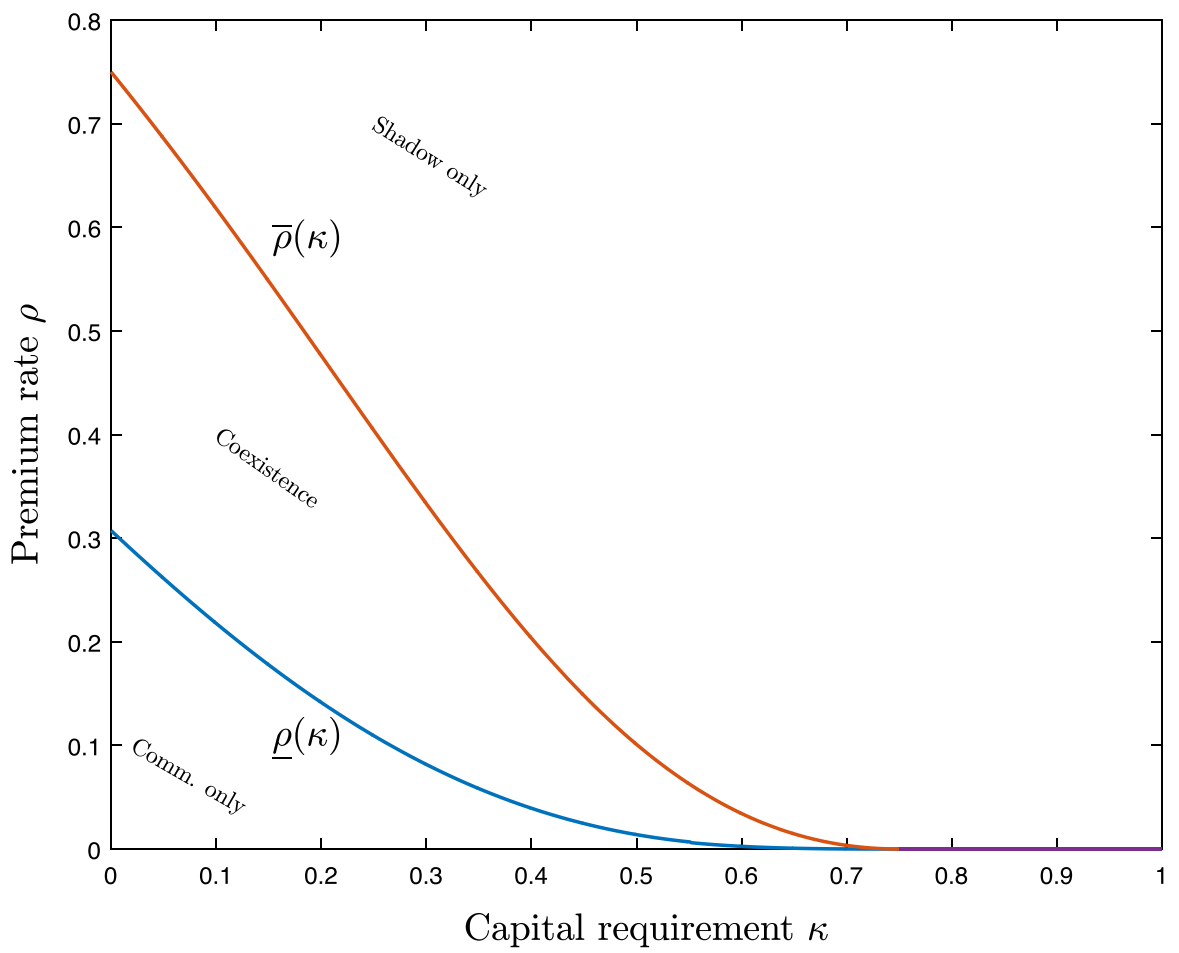

Fig. 7 Equilibrium regions under capital requirements with risky-asset-based premia. Again, agents are indifferent between creating commercial or shadow banks where the two curves meet, $\kappa \geq 0.75$. All breakdowns of banks into commercial and shadow is consistent with equilibrium for those values of $\kappa$. The equilibrium is trivially revenue neutral along the $\bar{\rho}(\kappa)$ curve

transfer from the deposit insurer. The date-1 relative price of the risky asset is lower for $\kappa=0.01$ than for $\kappa=0$, implying that the price distortion caused by deposit insurance decreases upon imposition of the capital requirement. In the numerical example we have $\pi_{1}(0.01)=1.356 .^{19}$

The same argument applies for higher values of $\kappa$. As the figures show, further increases in $\kappa$ lower $d^{*}(\kappa)$ and therefore decrease the value of creating commercial banks. Eventually $d^{*}(\kappa)$ equals $d^{I-I I}$, meaning that deposits at commercial banks are so low that each commercial bank can pay its depositors regardless of its realization of the shocks $\varepsilon_{1}$ and $\varepsilon_{2}$. At that value of the capital requirement, the equilibrium is as in Region I of the lump-sum case: (i) asset values equal the expected direct payoffs, (ii) agents are indifferent between directing their endowments to commercial or shadow banks, and (iii) deposit insurance is trivially revenue neutral. Further increases in $\kappa$ do not alter that equilibrium.

19 It should be noted that the decline in the date-1 relative price increases $d^{*}(\kappa)$, but by less than the decrease due to $\kappa$. Therefore the net effect of the increase in $\kappa$ on maximal deposits remains negative. In the numerical example we have that $d^{*}(0.01)=2.45$. 
Deposit-based premia The maximum admissible level of deposits now depends on the deposit-based insurance premium rate $\delta$ and the capital requirement $\kappa$. It is given by

$$
d^{*}(\delta, \kappa)=\frac{\bar{\varepsilon}\left(\underline{\varepsilon}+1 / \pi_{1}(\delta, \kappa)\right)}{1+\delta}(1-\kappa)
$$

which agrees with (17) if $\delta=0$, and agrees with (15) if $\kappa=0$. Under zero capital requirements we are back to the equilibrium derived in Sect. 3.3: all agents create commercial banks for low values of $\delta$, commercial and shadow banks coexist for intermediate $\delta$ and all agents create shadow banks for high $\delta$. The equilibrium for strictly positive capital requirements, $\kappa>0$, is similar to that equilibrium except that, as we will see, the intermediate region is degenerate in one case. The thresholds that demarcate low, intermediate and high values of $\delta$ depend on the capital requirement $\kappa$. The smallest value of $\delta$, given $\kappa$, at which individual agents are indifferent between creating commercial or shadow banks is denoted $\underline{\delta}(\kappa)$, as in Sect. 3.3 for $\kappa=0$. Similarly, $\bar{\delta}(\kappa)$ denotes the smallest value of $\delta$ at which deposit insurance is revenue neutral. Low values of delta correspond to $\delta \leq \underline{\delta}(\kappa)$, intermediate values to $\underline{\delta}(\kappa)<$ $\delta<\bar{\delta}(\kappa)$ and high values to $\bar{\delta}(\kappa) \leq \delta$.

Figure 6 shows how the equilibrium thresholds $\underline{\delta}(\kappa)$ and $\bar{\delta}(\kappa)$ change with the capital requirement $\kappa$. As with capital requirements in the lump-sum case, an increase in the capital requirement here decreases the size of the deposit insurance subsidy to each commercial bank. Therefore an increase in $\kappa$ makes shadow banking more attractive, relative to commercial banking. It follows that the threshold value of $\delta$ at which individual agents are indifferent between creating commercial and shadow banks is decreasing in the capital requirement$\underline{\delta}(\kappa)$ is a decreasing function of $\kappa$. The threshold $\bar{\delta}(\kappa)$ corresponds to the value of $\delta$ at which deposit insurance is revenue neutral: the aggregate subsidy to commercial banks equals zero along $\bar{\delta}(\kappa)$. Since the subsidy to commercial banks is decreasing in $\kappa$, we have that $\bar{\delta}(\kappa)$ is also a decreasing function of $\kappa$.

For very high levels of $\kappa$-equal to 0.55 in the numerical example - the set of values of $\delta$ for which commercial banks and shadow banks coexist reduces to a single point, that associated with nontrivial revenue neutrality. At these levels of $\kappa$ and $\delta, \pi_{1}$ equals the expected direct relative payoffs of risky and riskless assets, as in Region II as described in Sect. 3.2. Accordingly, agents creating shadow banks cannot sell risky assets at date 1 profitably. At the values of $\kappa$ and $\delta$ associated with revenue neutrality a small decrease in $\delta$ will motivate all agents to start commercial banks, and a small increase in $\delta$ will motivate all agents to start shadow banks.

For still higher levels of $\kappa$-those higher than 0.75 in the numerical exampledeposits are constrained so that no banks will fail, as in the corresponding case with lump-sum taxes. Agents will form commercial banks only if $\delta=0$; for $\delta>0$ all agents will form shadow banks. 
Risky-asset-based premia As with deposit-based premia, the maximum admissible level of deposits here depends on the insurance premium rate $\rho$ and the capital requirement $\kappa$. We have

$$
d^{*}(\rho, \kappa)=\left(\underline{\varepsilon}+1 / \pi_{1}(\rho, \kappa)\right)(\bar{\varepsilon}-\rho)(1-\kappa) .
$$

Again, these expressions for $d^{*}$ agree with earlier expressions in the special cases $\kappa=0$ and $\rho=0$. Under no capital requirement, $\kappa=0$, we recover the equilibrium derived in Sect. 3.4. The equilibrium under strictly positive capital requirements, $\kappa>0$, is qualitatively similar to the $\kappa=0$ equilibrium: all agents create commercial banks for low values of $\rho$, commercial and shadow banks coexist for intermediate values of $\rho$ and shadow banks dominate for high $\rho$. The capital requirement affects the thresholds that demarcate low, intermediate and high values of $\rho$. Similar to the case with deposit-based premia, for each value of $\kappa$, we define $\rho(\kappa)$ as the smallest value of the insurance premium rate $\rho$ at which individual agents are indifferent between creating commercial and shadow banks. Similarly, given $\kappa$, we define $\bar{\rho}(\kappa)$ as the smallest value of the insurance premium rate $\rho$ at which the deposit insurance program is revenue neutral. Low values of $\rho$ correspond to $\rho \leq \rho(\kappa)$, intermediate values correspond to $\underline{\rho}(\kappa)<\rho<\bar{\rho}(\kappa)$ and high values correspond to $\bar{\rho}(\kappa) \geq \rho$.

Figure 7 shows how the equilibrium thresholds $\rho(\kappa)$ and $\bar{\rho}(\kappa)$ depend on the capital requirement. As in the deposit-based case, the two thresholds are decreasing functions of the capital requirement $\kappa$. The intuition is the same: increasing $\kappa$ reduces the value of creating a commercial bank and makes shadow banking relatively more attractive. As with deposit-based premia, the two curves intersect. However, unlike depositbased premia, both the thresholds are equal to zero at the point of intersection. This difference reflects the fact that for very high levels of $\kappa$ the risky asset continues to sell at a discount at date-1, implying that agents creating shadow banks can buy risky assets at date 1 profitably. It is so because, at those levels of $\kappa$, high- $\varepsilon_{1}$ commercial banks (those that will never fail) strictly prefer to sell their risky assets and avoid the insurance premium when $\rho>0$. The two curves intersect when $\kappa$ is so high that no banks will fail $-\kappa=0.75$ in the numerical example. At that level of $\kappa$, commercial and shadow banks coexist only if $\rho=0$. Since no banks fail at that level of $\kappa$, deposit insurance is trivially revenue neutral.

\section{Discussion}

In this section we discuss the general features of our treatment of deposit insurance. We discuss how revenue neutrality guides deposit insurance design and compare it to actuarially fair insurance. We also discuss the role, generalizability and common objections to some of the assumptions we made in order to make the analysis tractable.

Distortions and welfare We found that the equilibrium asset prices are distorted whenever deposit insurance entails a net subsidy to banks. A government that wants to maximize social welfare would look to minimize distortions induced by deposit insurance. Agents in our setting are risk neutral, so all allocations are welfare-equivalent. 
Nevertheless, our analysis provides guidance on how to design deposit insurance that minimizes the associated price distortion. The distortion is minimized by revenue neutral deposit insurance, which entails a zero net subsidy to the banking system. It is possible to design nontrivial revenue neutral deposit insurance only when insurance premia are based on deposit levels. Therefore, our analysis suggests implementation of deposit-based over risk-based insurance premia, with the corresponding nontrivially revenue-neutral premium level.

Actuarially fair insurance premia also eliminate the distortion by removing the moral hazard associated with deposit insurance. However, it is unrealistic to assume that real-world deposit insurers can accurately measure changes in riskiness of individual banks' portfolios and are able and willing to adjust premia promptly in response to such changes. If one accepts that actuarially fair deposit insurance is unattainable, then the elimination of taxpayer subsidies to banks corresponds to revenue neutrality. The implementation of revenue neutral deposit insurance requires only that the common insurance premium be set such that the insurer balances its budget. This is similar to how insurance premia are implemented in practice. The insurance premia are generally charged in proportion to either deposits or holdings of risky assets, with the factor of proportionality being the same for all banks.

One agent one bank We assumed that each agent who elects to use commercial banks allocates his endowment of risky and riskless assets to his own personal bank. He receives in exchange deposits $d$ and bank equity $e_{0}^{c}$. When deposits are uninsured, agents who, contrary to this assumption, created deposits in banks other than those they own would run the risk that the equity holders in those banks would transfer risk to them after the deposit terms are set. This agency problem, which has been widely discussed in the finance literature (see John et al. (1991) for an application to deposit insurance), is the same agency problem we study, except that here the insurer takes the place of depositors as the bearer of the agency distortion. In the setting assumed here the agency problem between depositors and equity holders is avoided by creating separate banks, inasmuch as agents in their role as equity holders have no motive to exploit themselves in their role as depositors. We focus on the agency problem between depositors and the deposit insurer. When deposits are insured, each agent prefers creating his own bank so as to take maximum advantage of deposit insurance while avoiding conflicts of interest with other investors.

Bailouts Analysis of bailouts of financial institutions deals with issues similar to those involved with deposit insurance. ${ }^{20}$ The principal difference is that, as the name implies, deposit insurance applies only to deposits, not to non-deposit liabilities such as bonds, or to equity. In contrast, the goal of bailouts is to avoid bankruptcy. In practice this implies that bank obligations to most creditors are guaranteed, not just deposits. Also, in bailouts enough support is supplied to assure that bank equity continues to maintain considerable value. All our findings apply to bailouts, with "deposits" in the model being relabeled to include the appropriate non-deposit liabilities.

\footnotetext{
20 Keister (2016) is a recent study that applies insights from the deposit insurance literature to the analysis of bailouts.
} 
Shadow banks as subsidiaries In practice, generally, commercial banks created subsidiaries in order to participate in the shadow banking system; see e.g., Pozsar et al. (2013) for a description. In our model, however, commercial and shadow banks are distinct from each other. It is easy to modify the model such that shadow banks emerge as subsidiaries of commercial banks. Suppose that, instead of directing all their wealth to a commercial or shadow bank, each agent directs a proportion $\lambda$ of their wealth to a commercial bank and the remaining $1-\lambda$ to a shadow bank, while maintaining the ratio of risky to riskless assets at unity. Our results continue to apply in that setting provided we restrict attention to symmetric equilibria. Now, for intermediate values of deposit-based or risky-asset-based premia, agents will direct some of their wealth to shadow banks, with the exact proportion $1-\lambda$ determined by market clearing. These shadow banks can be interpreted as subsidiaries of commercial banks, as in reality.

\section{Conclusion}

We have shown that the design of the deposit insurance program has important implications for the structure of the financial system. When deposit insurance is financed entirely via lump-sum taxes commercial banks dominate shadow banks. We also considered deposit insurance financed, at least partially, by premia based on deposit levels or risky asset holdings. In that case, for extremely low levels of the premium all wealthholders direct their assets to commercial banks, while for extremely high levels they direct assets to shadow banks. For a range of intermediate premium levels, commercial and shadow banks coexist under subsidized deposit insurance, with the measure of each bank determined by the insurance premium level. This result arises because of free entry plus the fact that shadow banks can trade advantageously due to price distortions induced by commercial banks gaming the deposit insurance program. Therefore, we found that subsidized deposit insurance directly benefits commercial banks and indirectly benefits shadow banks.

We analyzed how capital requirements on commercial banks affect the structure of the financial system, under all three insurance premium regimes. We found that capital requirements make shadow banking more attractive by lowering the deposit insurance subsidy to commercial banks. If the capital requirement is high enough, we saw that commercial and shadow banks coexist in equilibrium. Extremely high capital requirements put commercial banks at a competitive disadvantange: all agents direct their assets to the shadow banks.

Our general equilibrium setting allowed us to determine how deposit insurance affects asset prices. We found that equilibrium asset prices are distorted whenever deposit insurance is revenue favorable to commercial banks, meaning that the aggregate subsidy to commercial banks is positive. Our conclusion that asset prices are distorted as a consequence of deposit insurance to the extent that the insurance program is financed using lump-sum taxes is surprising inasmuch as lump-sum taxes are usually associated with the absence of distortion, not its presence. The resolution of this anomaly lies in the fact that we are dealing with a general equilibrium model: in our setting lump-sum taxes are essentially the same thing (via the budget identities and market-clearing conditions) as the subsidy implied by underpriced deposit insurance. 
Accordingly, saying that lump-sum taxation causes the distortion is essentially the same thing as saying that underpriced deposit insurance causes the distortion.

Presumably government agencies that insure bank deposits wish to minimize distortions induced by the insurance. In the present context this consideration favors implementation of revenue-neutral deposit insurance. However, we observed that, depending on the precise specification, there may or may not exist equilibria that are nontrivially revenue neutral. A matter that requires further investigation is which version of the model is closer to the real world, the one that has nontrivial revenueneutral equilibria or that which does not. That investigation is particularly important if proposals to base deposit insurance on holdings of risky assets, or to extend deposit insurance to institutions other than commercial banks, are implemented. The analysis of risky-asset-based premia presented here also provides an important caveat for the design of such proposals: deposit insurance that results in risk being transferred from one class of institution to another serves no social purpose, at least to the extent that uninsured institutions are vulnerable to bank runs.

We believe that our conclusions do not depend critically on our simplifying assumptions, although the demonstrations of their validity would be more complex in less restricted settings. If so, the exercise reported in this paper provides a useful guide in thinking about real-world regulation of the banking system. Making the transition from toy models such as ours to reality involves replacing the stylized model of this paper with a more general model that connects more closely with the real world. Such a model could in principle be calibrated, leading to conclusions that can be taken seriously empirically. We think that attempting to do so is an appropriate direction for future work.

Acknowledgements We would like to thank the Editor and one anonymous referee for helpful comments. We are also indebted to Kartik Athreya, Jan Auerbach, Gadi Barlevy, Philip Bond, Tom Cooley, Huberto Ennis, Fred Furlong, Rod Garratt, Itay Goldstein, Borys Grochulski, Miguel Delgado Helleseter, Yoske Igarashi, Jack Kareken, Dave Kelly, Nobu Kiyotaki, Frederic Malherbe, Julian Neira, Ned Prescott, Jan Uboe, Stephane Verani, Neil Wallace, Zhenyu Wang and seminar participants at UC Santa Barbara, the Federal Reserve Bank of San Francisco, the 2013 Federal Reserve Bank of Chicago Summer Workshop on Money, Banking, Payments and Finance, the Federal Reserve Board, the Federal Reserve Bank of Richmond, the Federal Deposit Insurance Corporation, 2015 Midwest Macroeconomics Meetings, 2015 LAEF Business CYCLE Conference, London FIT workshop, 2016 Exeter Workshop on Macroeconomics and Banking, and IADI 2017 Biennial Research Conference for helpful discussions.

Open Access This article is licensed under a Creative Commons Attribution 4.0 International License, which permits use, sharing, adaptation, distribution and reproduction in any medium or format, as long as you give appropriate credit to the original author(s) and the source, provide a link to the Creative Commons licence, and indicate if changes were made. The images or other third party material in this article are included in the article's Creative Commons licence, unless indicated otherwise in a credit line to the material. If material is not included in the article's Creative Commons licence and your intended use is not permitted by statutory regulation or exceeds the permitted use, you will need to obtain permission directly from the copyright holder. To view a copy of this licence, visit http://creativecommons.org/licenses/by/4.0/.

\section{References}

Acharya, V.V., Schnabl, P., Suarez, G.: Securitization without risk transfer. J Financ Econ 107(3), 515-536 (2013) 
Adrian, T., Ashcraft, A.B.: Shadow banking: a review of the literature. Staff Report 580, Federal Reserve Bank of New York (2012)

Adrian, T., Shin, H.S.: The changing nature of financial intermediation and the financial crisis of 2007-09. Staff Report 439, Federal Reserve Bank of New York (2010)

Allen, F., Gale, D.: Bubbles and crises. Econ J 110(460), 236-55 (2000)

Allen, F., Gorton, G.: Churning bubbles. Rev Econ Stud 60(4), 813-36 (1993)

Allen, F., Carletti, E., Marquez, R.: Deposits and bank capital structure. J Financ Econ 118(3), 601-619 (2015)

Barlevy, G.: A leverage-based model of speculative bubbles. J Econ Theory 153(C), 459-505 (2014)

Brunnermeier, M.K., Oehmke, M.: Chapter 18-Bubbles, Financial Crises, and Systemic Risk, Part B of Handbook of the Economics of Finance, vol. 2, pp. 1221-1288. Elsevier, Amsterdam (2013)

Demirguc-Kunt, A., Kane, E.J.: Deposit insurance around the globe: where does it work? J Econ Perspect 16(2), 175-195 (2002)

Demirguc-Kunt, A., Kane, E.J., Laeven, L.: Determinants of deposit-insurance adoption and design. J Financ Intermed 17(3), 407-438 (2008)

Dow, J., Han, J.: Contractual incompleteness, limited liability and asset price bubbles. J Financ Econ 116(2), 383-409 (2015)

Duffie, D., Sun, Y.: Existence of independent random matching. Ann Appl Probab 17, 386-419 (2007)

Duffie, D., Sun, Y.: The exact law of large numbers for independent random matching. J Econ Theory 147, 1105-1139 (2012)

Feldman, M., Gilles, C.: An expository note on individual risk without aggregate uncertainty. J Econ Theory 35, 26-32 (1985)

Górnicka, L.: Banks and shadow banks: competitors or complements? J Financ Intermed 27, 118-131 (2016)

Gorton, G.: Slapped by the Invisible Hand: The Panic of 2007. Oxford University Press, Oxford (2010)

Gorton, G., Metrick, A.: Chapter 1-Securitization, Part A of Handbook of the Economics of Finance, vol. 2, pp. 1-70. Elsevier, Amsterdam (2013)

Grochulski, B., Zhang, Y.: Optimal liquidity regulation with shadow banking. Working paper 15-12, Federal Reserve Bank of Richmond (2016)

Hanson, S., Shleifer, A., Stein, J.C., Vishny, R.W.: Banks as patient fixed-income investors. J Financ Econ 117(3), 449-469 (2015)

Harris, M., Opp, C.C., Opp, M.M.: The system-wide effects of bank capital regulation on credit supply and risk-taking. Working paper. https://ssrn.com/abstract=2467761 (2015)

John, K., John, T.A., Senbet, L.W.: Risk-shifting incentives of depository institutions: a new perspective on federal deposit insurance reform. J Bank Finance 15(4-5), 895-915 (1991)

Judd, K.L.: The law of large numbers with a continuum of IID random variables. J Econ Theory 35, 19-25 (1985)

Kareken, J.H.: Deposit insurance reform or deregulation is the cart, not the horse. Fed Reserve Bank Minneap Q Rev 7(Spring), 1-9 (1983)

Kareken, J.H., Wallace, N.: Deposit insurance and bank regulation: a partial-equilibrium exposition. J Bus 51, 413-438 (1978)

Kashyap, A.K., Stein, J.C., Hanson, S.: An analysis of the impact of substantially heightened capital requirements on large financial institutions. Booth School of Business, University of Chicago, reproduced (2010)

Keeley, M.C., Furlong, F.T.: A reexamination of mean-variance analysis of bank capital regulation. J Bank Finance 14, 69-84 (1990)

Keister, T.: Bailouts and financial fragility. Rev Econ Stud 83(2), 704-736 (2016)

Luck, S., Schempp, P.: Banks, shadow banking, and fragility. Working paper series 1726, European Central Bank, August (2014)

Lyonnet, V., Chrétien, E.: Traditional and shadow banks during the crisis. https://ssrn.com/abstract=2903884 (2017)

Merton, R.C.: An analytic derivation of the cost of deposit insurance and loan guarantees: an application of modern option pricing theory. J Bank Finance 1(1), 3-11 (1977)

Ordonez, G.: Sustainable shadow banking. Am Econ J Macroecon 10(1), 33-56 (2018)

Plantin, G.: Shadow banking and bank capital regulation. Rev Financ Stud 28(1), 146-175 (2015)

Pozsar, Z., Adrian, T., Ashcraft, A.B., Boesky, H.: Shadow banking. Federal Reserve Bank of New York Economic Policy Review (2013) 
Prescott, E.S.: Can risk-based deposit insurance premiums control moral hazard? Econ Q 88, 87-100 (2002) Pyle, D.H.: Deregulation and deposit insurance reform. Econ Rev 2(Spring), 5-15 (1984)

Suarez, J.: Banking regulation in an equilibrium model. PhD dissertation (1993)

Uhlig, H.: A law of large numbers for large economies. Econ Theor 8, 41-50 (1996)

Publisher's Note Springer Nature remains neutral with regard to jurisdictional claims in published maps and institutional affiliations. 